Article

\title{
Antimicrobial Paper Coatings Containing Microencapsulated Cymbopogon citratus Oil
}

\author{
Boštjan Šumiga ${ }^{1}$, Barbara Šumiga ${ }^{2}$, David Ravnjak ${ }^{3}$ and Bojana Boh Podgornik ${ }^{1, *}$ \\ 1 Faculty of Natural Sciences and Engineering, University of Ljubljana, 1000 Ljubljana, Slovenia \\ 2 Pulp and Paper Institute, 1000 Ljubljana, Slovenia \\ 3 Papirnica Vevče d. o. o., 1262 Ljubljana-Dobrunje, Slovenia \\ * Correspondence: bojana.boh@ntf.uni-lj.si; Tel.: +386-1-2003-257
}

Received: 18 June 2019; Accepted: 23 July 2019; Published: 25 July 2019

check for updates

\begin{abstract}
Essential oils are environmentally friendly candidates for antimicrobial smart packaging systems. Encapsulation is needed to reduce their volatility and achieve controlled release. Within this study, the essential oil of Cymbopogon citratus (citronella oil) was microencapsulated and applied in pressure-sensitive antimicrobial functional coatings on papers for secondary packaging. Two microencapsulation methods were used: complex coacervation of gelatine with carboxymethylcellulose or with gum arabic, and in situ polymerization of melamine-formaldehyde prepolymers with a polyacrylic acid modifier. Minimum inhibitory concentrations of citronella oil microcapsules were determined for Bacillus subtilis (B. subtilis), Escherichia coli (B. subtilis), Pseudomonas aeruginosa (P. aeruginosa) and Saccharomyces cerevisiae (S. cerevisiae). Microcapsule suspensions were coated on papers for flexible packaging, 2 and $30 \mathrm{~g} / \mathrm{m}^{2}$, and mechanically activated in the weight pulling test. A novel method on agar plates in sealed Petri dishes was developed to evaluate the antimicrobial activity of released citronella vapours on E. coli and S. cerevisiae. The results showed that both microencapsulation methods were successful and resulted in a container type single-core microcapsules. In situ microcapsule suspensions had better paper coating properties and were selected for industrial settings. The antimicrobial activity of $2 \mathrm{~g} / \mathrm{m}^{2}$ coatings was not detected; however, the antimicrobial activity of $30 \mathrm{~g} / \mathrm{m}^{2}$ partially activated coated papers was confirmed. The product enabled a prolonged use with the gradual release of citronella oil at multiple exposures of functional papers to pressure, e.g., by a human hand during product handling.
\end{abstract}

Keywords: antimicrobial paper; Cymbopogon citratus; essential oil; microcapsules; coacervation; in situ polymerization; coating; morphology; antimicrobial tests

\section{Introduction}

\subsection{Microencapsulation in Paper Industries}

The first commercialization of the microencapsulation technology comes from the paper industry, from the production of pressure-sensitive carbonless copy papers in 1951. By the end of the 1950s, microencapsulation found its use in the pharmaceutical industry, as well as in technical applications. Since then, the technology has been constantly improving, modified and adapted for a variety of purposes and uses. In the beginning, microencapsulation was viewed more as art or technical know-how than as a "real" science with fundamental academic research. However, recent trends in patents and scientific journal articles on microencapsulation show balanced growth of both, scientific research and patented industrial inventions (cf. Figure 1). 


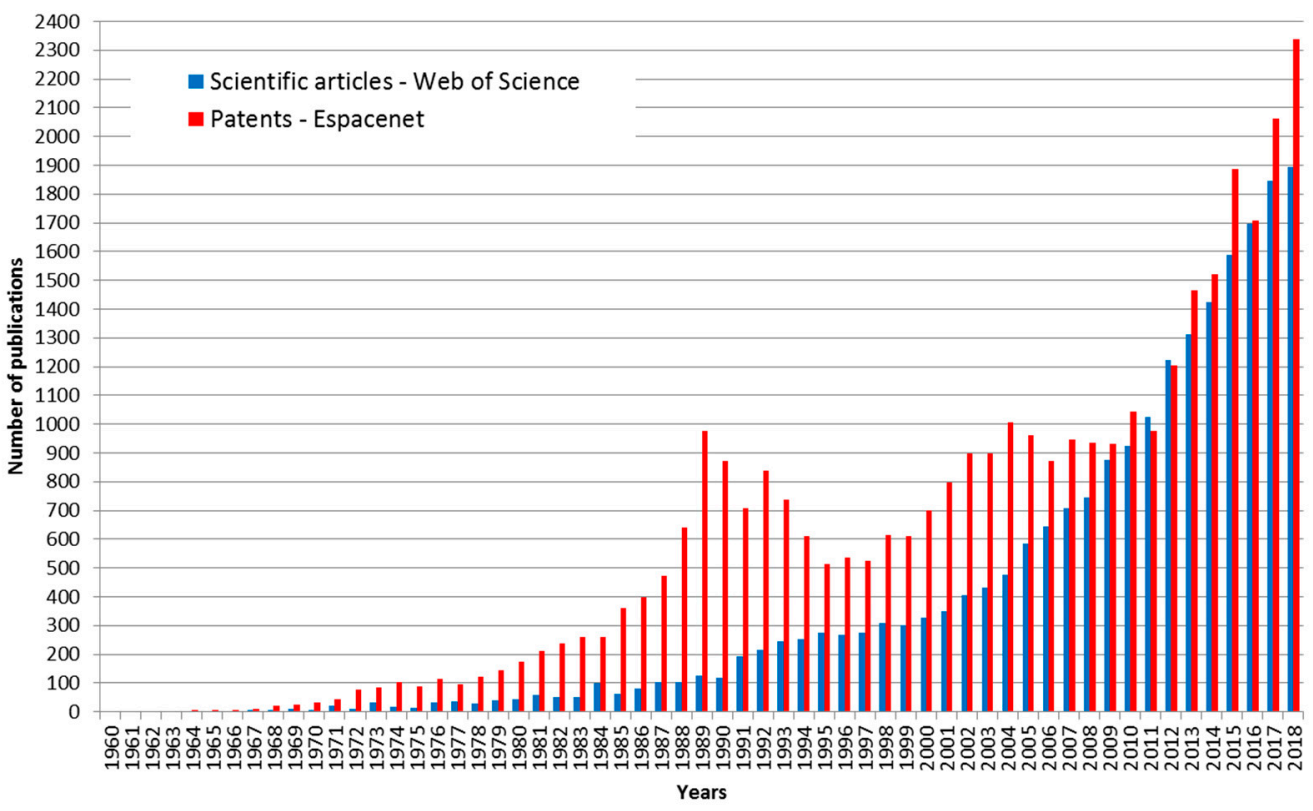

Figure 1. Annual number of new publications on microencapsulation (Web of Science and Espacenet databases, search profile: microcapsul* OR microencapsul*).

Many microencapsulation processes and applications have been developed and described [1-3]. In paper industries, typical microencapsulation applications include pressure-sensitive copying papers, thermochromic and photosensitive papers, electronic paper, fragranced papers, antimicrobial paper products and additives for smart packaging (cf. Table 1).

Table 1. Identified topics of microencapsulation in paper industries for functional papers.

\begin{tabular}{|c|c|c|}
\hline Application/Topic & Examples & References \\
\hline $\begin{array}{l}\text { Pressure-sensitive copying } \\
\text { paper }\end{array}$ & $\begin{array}{c}\text { multi-layered business forms, security papers, labels, } \\
\text { single-layer pressure and heat-sensitive recording paper, } \\
\text { self-contained printing inks, forgery-resistant back } \\
\text { carbon ink }\end{array}$ & [4-8] \\
\hline Fragranced papers & $\begin{array}{l}\text { fragranced printing paper, promotional materials, sticky } \\
\text { notes, scented tissue paper, aromatherapy, cigarette } \\
\text { paper, gift box paper }\end{array}$ & [9-13] \\
\hline $\begin{array}{l}\text { Thermochromic and } \\
\text { photosensitive papers }\end{array}$ & $\begin{array}{l}\text { thermochromic papers, UV fixable thermal films, two } \\
\text { colour thermal papers, thermally fixing } \\
\text { photosensitive papers }\end{array}$ & {$[14-16]$} \\
\hline $\begin{array}{l}\text { Antimicrobial paper } \\
\text { products }\end{array}$ & $\begin{array}{l}\text { hygiene papers, wallpapers, wrapping papers, } \\
\text { disposable paper sheets, disposable wiping papers, } \\
\text { antibacterial regenerated artificial leather paper, } \\
\text { antimicrobial waterproofing paper, data carrier products }\end{array}$ & [17-24] \\
\hline Smart packaging & $\begin{array}{l}\text { functional paper packaging for agricultural products, } \\
\text { antibacterial and antioxidative packaging papers, smart } \\
\text { food packaging containing phase change materials, } \\
\text { medical heat-sensitive papers, smart container for food } \\
\text { and fluids with temperature detection }\end{array}$ & [25-29] \\
\hline Insulation papers & paper formulations for gypsum building boards & [30] \\
\hline Recyclable papers & $\begin{array}{l}\text { deinking of waste paper with } \\
\text { microencapsulated enzymes }\end{array}$ & {$[31]$} \\
\hline Electronic papers & $\begin{array}{l}\text { electronic papers based on microencapsulated liquid } \\
\text { crystals or microencapsulated pigments }\end{array}$ & [32-34] \\
\hline
\end{tabular}




\subsection{Microencapsulated Antimicrobial Essential Oils}

During recent years, the interest in the bio-efficacy of essential oils and their uses as natural antimicrobials in environmentally friendly products has rapidly increased. Several authors have reported on innovations in smart packaging food systems based on essential oils [35-41]. Among essential oils, the oil obtained from lemongrass plants of genus Cymbopogon, particularly of C. citratus (CAS RN 8000-29-1) known as citronella or lemongrass oil, has been studied and used due to its broad-spectrum antimicrobial activity, pleasant aroma and uses in food, pharmaceutical and cosmetic products, as well as in mosquito repellents and natural pesticides.

Citronella oil predominantly consists of monoterpenes, such as citral (synonym geranial) (39\%-48\%), neral (32\%-35\%), mircen (11\%-15\%) and geraniol (3\%-5\%) [42-45] and has a boiling point at $222{ }^{\circ} \mathrm{C}$, specific weight 0.897 and oral $\mathrm{LD}_{50}$ for rat $4400 \mathrm{mg} / \mathrm{kg}$ [46]. As the components of essential oil are volatile and subject to degradation under environmental influences, encapsulation techniques and delivery systems may be applied to provide protection and prolonged or controlled release, including microcapsules and microspheres, nanoparticles and nanospheres, liposomes, microemulsions, gels and molecular inclusions [47-51]. Among them, microcapsules seem to be the first choice for technical applications, including in paper and print industries [52].

The analysis of scientific literature reveals that citronella oil can be microencapsulated for different applications and by using various microencapsulation methods (cf. Table 2). Nevertheless, the antimicrobial evaluation of citronella oil in microencapsulated forms or products seems to be more complex and was reported only in few publications (cf. Table 3). None of them reported on the antimicrobial evaluation of citronella oil, encapsulated in impermeable yet pressure-sensitive microcapsules that require a mechanical activation to release the active ingredient.

Table 2. Review of citronella oil microencapsulation methods with suggested applications.

\begin{tabular}{|c|c|c|c|}
\hline Authors & Method and Wall Materials & Microcapsule Sizes & Applications \\
\hline Leimann et al. [54] & $\begin{array}{l}\text { simple coacervation of poly(vinyl } \\
\text { alcohol) }\end{array}$ & $10-250 \mu \mathrm{m}$ & antimicrobial \\
\hline Miro Specos et al. [55] & $\begin{array}{l}\text { complex coacervation of gelatine and } \\
\text { gum arabic }\end{array}$ & 25-100 $\mu \mathrm{m}$ & $\begin{array}{l}\text { mosquito repellent } \\
\text { finishing of cotton } \\
\text { textiles }\end{array}$ \\
\hline Solomon et al. [56] & $\begin{array}{l}\text { simple coacervation of gelatine by } \\
\text { sodium sulphate }\end{array}$ & no data & $\begin{array}{l}\text { mosquito repellent } \\
\text { topical } \\
\text { formulations-ointments }\end{array}$ \\
\hline Liu et al. [57] & $\begin{array}{l}\text { complex coacervation of gelatine and } \\
\text { gum arabic }\end{array}$ & $10 \mu \mathrm{m}$ & $\begin{array}{l}\text { antimicrobial cotton } \\
\text { fabrics }\end{array}$ \\
\hline Bezerra et al. [59] & $\begin{array}{l}\text { complex coacervation of gelatine and } \\
\text { gum arabic }\end{array}$ & $1-18 \mu \mathrm{m}$ & $\begin{array}{l}\text { textiles: cotton and } \\
\text { polyester fabrics }\end{array}$ \\
\hline Ribeiro et al. [60] & $\begin{array}{l}\text { interfacial polymerization of isocyanate } \\
\text { and 1,4-butene-diol; polyurethane wall } \\
\text { functionalisation with } \mathrm{TiO}_{2} \\
\text { nanoparticles }\end{array}$ & $50-250 \mu \mathrm{m}$ & $\begin{array}{l}\text { solar-activated } \\
\text { controlled release } \\
\text { mosquito repellents }\end{array}$ \\
\hline Bustos et al. [38] & $\begin{array}{l}\text { emulsification-separation method, } \\
\text { sodium caseinate wall }\end{array}$ & average $22 \mu \mathrm{m}$ & $\begin{array}{l}\text { edible antimicrobial } \\
\text { films for food products }\end{array}$ \\
\hline Khounvilay et al. [61] & $\begin{array}{l}\text { spray drying, carboxymethylated } \\
\text { tamarind gum walls }\end{array}$ & $3.8-6.3 \mu \mathrm{m}$ & not specified \\
\hline
\end{tabular}


Table 2. Cont.

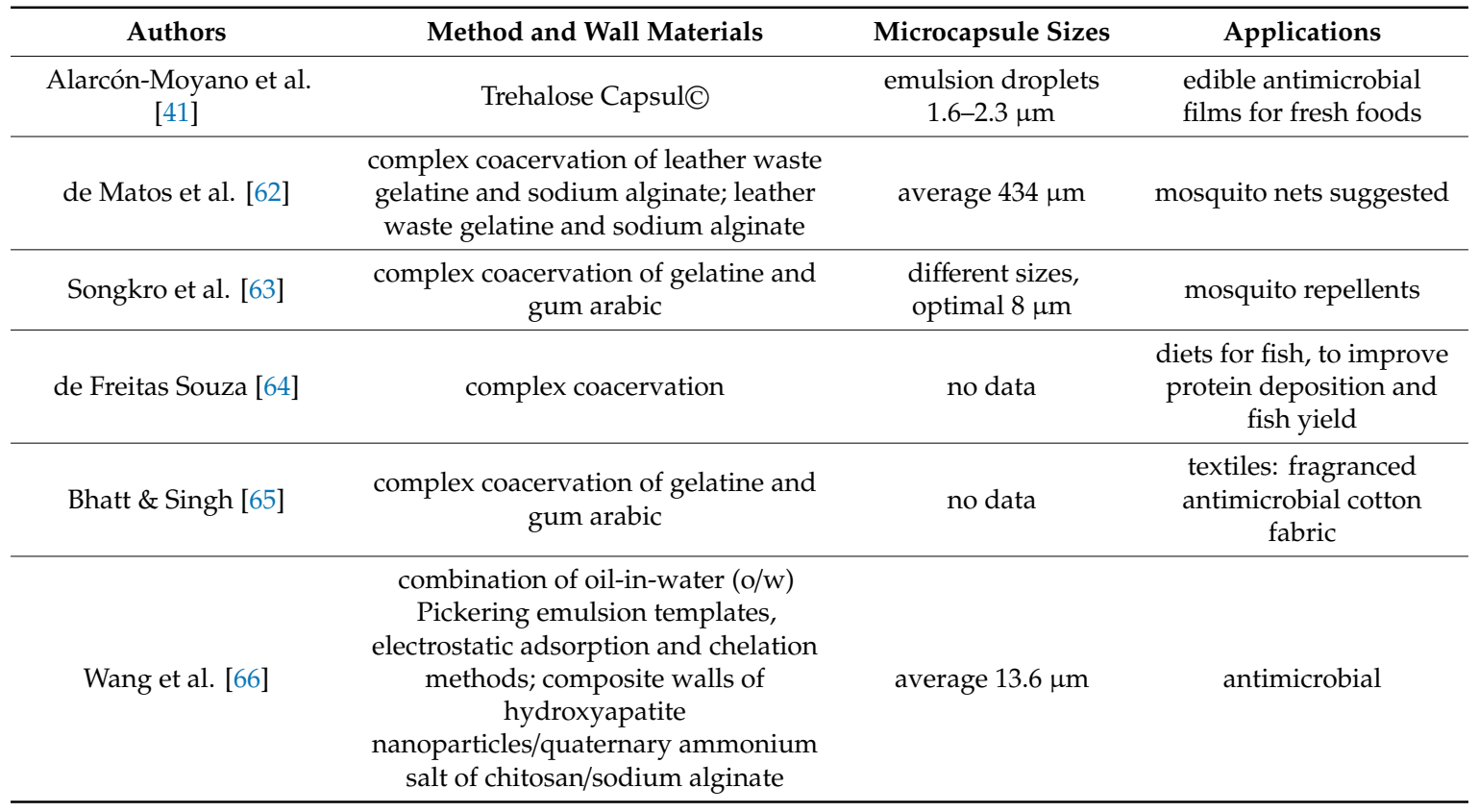

Table 3. Reported antimicrobial activities and minimum inhibitory concentration (MIC) values of microencapsulated citronella oil or corresponding products.

\begin{tabular}{|c|c|c|}
\hline Reference & Antimicrobial Assay & Results \\
\hline Leimann et al. [54] & $\begin{array}{l}\text { Microdilution method in } \\
\text { liquid media, with dimethyl } \\
\text { sulfoxide (DMSO) }\end{array}$ & $\begin{array}{c}\text { MIC of pure citronella oil: Escherichia coli } 22.32 \\
\text { mg/mL, Staphylococcus aureus } 22.32 \mathrm{mg} / \mathrm{mL} ; \\
\text { MIC of citronella oil extracted from } \\
\text { microcapsules: Escherichia coli } 2.79 \mathrm{mg} / \mathrm{mL} \text {, } \\
\text { Staphylococcus aureus } 2.79 \mathrm{mg} / \mathrm{mL}\end{array}$ \\
\hline Liu et al. [57] & $\begin{array}{l}\text { shake flask method GB } \\
\text { 15979-2002 and agar plates }\end{array}$ & $\begin{array}{c}\text { confirmed antibacterial properties of fabrics } \\
\text { with microencapsulated citronella oil (no } \\
\text { quantitative data) }\end{array}$ \\
\hline Bustos et al. [38] & $\begin{array}{l}\text { Multiscan Go device with well } \\
\text { plates, liquid cultures }\end{array}$ & $\begin{array}{l}\text { inhibited growth of Escherichia coli and Listeria } \\
\text { monocytogenes at } 1250 \mathrm{ppm} \text { citronella oil } \\
\text { concentration in the film; equivalent to } 5 \mathrm{ppm} \\
\text { citronella oil concentration in the medium after } \\
10 \mathrm{~h} \text { of incubation }\end{array}$ \\
\hline $\begin{array}{l}\text { Alarcón-Moyano et al. } \\
\text { [41] }\end{array}$ & $\begin{array}{c}1 \mathrm{~cm}^{2} \text { pieces of film placed on } \\
\text { agar plates inoculated with } E . \\
\text { coli }\end{array}$ & $\begin{array}{l}\text { MIC of alginate-citronella oil suspension film: } \\
\text { Escherichia coli } 0.3 \% v / v ; \\
\text { MIC of the film without citronella oil: } 0.6 \% v / v\end{array}$ \\
\hline Bhatt \& Singh [65] & $\begin{array}{l}\text { AATCC } 100 \\
\text { method-Assessment of } \\
\text { Antibacterial Finishes on } \\
\text { Textile Materials }\end{array}$ & $\begin{array}{c}80 \% \text { reduction in bacterial colonies in citronella } \\
\text { oil microcapsule treated fabric, compared to } \\
\text { non-treated fabric }\end{array}$ \\
\hline Wang et al. [66] & $\begin{array}{l}\text { Disc-diffusion (agar plates) } \\
\text { and MIC method }\end{array}$ & $\begin{array}{c}\text { MIC of microcapsules: Escherichia coli } 0.625 \\
\mathrm{mg} / \mathrm{mL} \text {, Staphylococcus aureus } 0.625 \mathrm{mg} / \mathrm{mL} ; \\
\text { MIC of walls-empty microcapsules: } \\
\text { Escherichia coli } 2.25 \mathrm{mg} / \mathrm{mL} \text {, Staphylococcus } \\
\text { aureus } 2.25 \mathrm{mg} / \mathrm{mL}\end{array}$ \\
\hline
\end{tabular}

Authors have used different antimicrobial tests and methodologies to evaluate the antimicrobial activity of citronella oil, mainly in the non-encapsulated form. Vázquez-Sánchez et al. [67] evaluated the activity of 19 essential oils against pathogenic Staphylococcus aureus biofilms in food-processing facilities 
and demonstrated that citronella oil was the second most effective, with the minimum inhibitory concentration (MIC) being 0.06\%, after thyme oil (MIC 0.04\%). Saddiq and Khayyat [68] determined the biological activity of citronella oil with the agar-well diffusion method; the inhibition zones 3.5, 2.6 and $1.8 \mathrm{~mm}$ were detected for Staphylococcus aureus, Penicillium italicum and Rhizopus stolonifer, respectively. The study by Ohno et al. [69] demonstrated that lemongrass oil was able to inhibit growth of Helicobacter pylori, a pathogen responsible for gastroduodenal diseases, at $0.01 \%$ concentration. The resistance did not develop even after 10 sequential passages, whereas the resistance to antibiotic clarithromycin developed under the same conditions. Naik et al. [70] determined MIC and minimum bactericidal concentration (MBC) values of citronella oil for pathogenic microorganisms Staphylococcus aureus (MIC 0.03\%, MBC 0.06\%), Bacillus cereus (MIC 0.03\%, MBC 0.06\%), Bacillus subtilis (MIC 0.06\%, MBC $0.12 \%$ ), Escherichia coli (MIC 0.06\%, MBC 0.12\%) and Klebsiella pneumoniae (MIC 0.25\%, MBC 0.50\%). For Pseudomonas aeruginosa, MIC and MBC could not be determined in the applied concentration range. Citronella oil was also effective against some microorganisms resistant to antibiotics; therefore, the authors suggested using citronella oil in the treatment of infections caused by multidrug-resistant organisms. The results also suggested that Gram-positive organisms were more sensitive to citronella oil than Gram-negative organisms and that the values also depended on the method used-the microorganisms were inhibited at lower concentrations using the broth dilution method as compared to the agar diffusion method.

\subsection{Research Aim and Objectives}

The aim of our research was to develop a pressure-sensitive controlled-release microencapsulated form of citronella oil to use it as a functional additive in paper and cardboard secondary packaging systems for food and pharmaceuticals. The objectives were (a) synthesis of microcapsules with two methods, complex coacervation and in situ polymerization, (b) preparation of coating formulations and implementation of coating on paper, (c) characterisation of microcapsules and of coated papers, (d) mechanical activation of pressure-sensitive microcapsules on papers, and (e) antimicrobial evaluation of citronella oil microcapsules and coated papers.

\section{Materials and Methods}

\subsection{Microencapsulation with Complex Coacervation}

Microencapsulation of essential oils with complex coacervation has already been described $[55,62,63]$. In our modified complex coacervation process, acid-treated gelatine (Gelatin from porcine skin, gel strength 30, type A; Sigma-Aldrich, St. Louis, MO, USA), and low viscosity carboxymethylcellulose, type 7L (Hercules, Wilmington, DE, USA), or gum arabic (Gum arabic from acacia tree, Sigma-Aldrich, Saint-Quentin Fallavier, France), were used as macromolecular colloids with opposite charges for the formation of microcapsule walls. Citronella oil-Java (Sigma-Aldrich, St. Louis, $\mathrm{MO}, \mathrm{USA}$ ) was used as the microcapsule core in all experiments except in the case of a blank for antimicrobial testing where microcapsules without a core were produced in a thermostated reactor vessel (Termoproc VKNO, Labo, Ljubljana, Slovenia) with an overhead stirrer turbine impeller (Heidolph RZR 2020, Heidolph Instruments, Schwabach, Germany). The temperature was maintained at $T=50^{\circ} \mathrm{C}$. The emulsification took place at $600-800 \mathrm{rpm}, 10-30 \mathrm{~min}$. To form microcapsules, the coacervation was initiated with dilution with water and by lowering $\mathrm{pH}$ to $3.9-4.3\left(1-2 \mathrm{~h}, \mathrm{~T}=50^{\circ} \mathrm{C}, 600-800 \mathrm{rpm}\right)$. After cooling the system to room temperature $\left(1^{\circ} \mathrm{C} / \mathrm{min}, 600-800 \mathrm{rpm}\right)$, the coacervate walls were crosslinked by glutaraldehyde (Acros Organics, Geel, Belgium) or by tannin (Tanin Sevnica, Sevnica, Slovenia); the process was completed after $2 \mathrm{~h}$. Detailed parameters of coacervation experiments are provided in Table 4. Experiments without the addition of the core material were performed under the same conditions. 
Table 4. Experimental parameters of citronella oil complex coacervation microencapsulation for gelatine-carboxymethyl cellulose (G-CMC) and gelatine-gum arabic (G-GA) systems.

\begin{tabular}{|c|c|c|c|c|c|}
\hline \multirow{2}{*}{ Parameters } & \multicolumn{5}{|c|}{ Batch Codes } \\
\hline & G-CMC-1 & G-GA-6 & G-GA-7 & G-GA-8 & G-GA-9 \\
\hline Water (g) & 80 & 125.0 & 125.0 & 125.0 & 125.0 \\
\hline Gelatine (g) & 10 & 2.5 & 2.5 & 2.5 & 2.5 \\
\hline $\begin{array}{l}\text { Sodium dodecyl } \\
\text { sulphate }(\mathrm{g})\end{array}$ & 0.0 & 0.0 & 0.1 & 0.0 & 0.1 \\
\hline Citronella oil (g) & 40.0 & 30.0 & 30.0 & 30.0 & 30.0 \\
\hline Emulsification & $\begin{array}{l}800 \mathrm{rpm}, \\
10 \mathrm{~min}\end{array}$ & $\begin{array}{l}600 \mathrm{rpm}, \\
30 \mathrm{~min}\end{array}$ & $\begin{array}{l}600 \mathrm{rpm}, \\
30 \mathrm{~min}\end{array}$ & $\begin{array}{l}600 \mathrm{rpm}, \\
30 \mathrm{~min}\end{array}$ & $\begin{array}{l}600 \mathrm{rpm}, \\
30 \mathrm{~min}\end{array}$ \\
\hline $\begin{array}{l}\text { Carboxymethyl } \\
\text { cellulose } 2 \% \text { aq. } \\
\text { solution (g) }\end{array}$ & 160.0 & 0.0 & 0.0 & 0.0 & 0.0 \\
\hline Gum arabic (g) & 0.0 & 2.5 & 2.5 & 2.5 & 2.5 \\
\hline Water $(\mathrm{g})$ & 170.0 & 125.0 & 125.0 & 125.0 & 125.0 \\
\hline $10 \%$ acetic acid $(\mathrm{g})$ & 2.5 & 2.0 & 2.0 & 2.0 & 2.0 \\
\hline Coacervation & $\begin{array}{c}\text { pH 4.3, } \\
800 \mathrm{rpm}, 2 \text { h }\end{array}$ & $\begin{array}{c}\mathrm{pH}=3.9 \\
600 \mathrm{rpm}, 1 \mathrm{~h}\end{array}$ & $\begin{array}{c}\mathrm{pH}=3.9 \\
600 \mathrm{rpm}, 1 \mathrm{~h}\end{array}$ & $\begin{array}{c}\mathrm{pH}=3.9 \\
600 \mathrm{rpm}, 1 \mathrm{~h}\end{array}$ & $\begin{array}{c}\mathrm{pH}=3.9 \\
600 \mathrm{rpm}, 1 \mathrm{~h}\end{array}$ \\
\hline $\begin{array}{c}25 \% \\
\text { glutaraldehyde }(\mathrm{g})\end{array}$ & 3.0 & 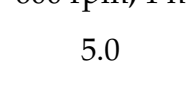 & 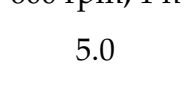 & 0.0 & 0.0 \\
\hline $10 \%$ tannin $(\mathrm{g})$ & 0 & 0.0 & 0.0 & 10.0 & 10.0 \\
\hline $\begin{array}{c}\text { Core in final } \\
\text { suspension }(\%)\end{array}$ & 8.59 & 10.3 & 10.3 & 10.1 & 10.1 \\
\hline $\begin{array}{c}\text { Wall in final } \\
\text { suspension (\%) }\end{array}$ & 2.84 & 1.71 & 1.71 & 1.68 & 1.68 \\
\hline $\begin{array}{l}\text { Microcapsule } \\
\text { core/wall ratio }\end{array}$ & 3.0 & 6.0 & 6.0 & 6.0 & 6.0 \\
\hline
\end{tabular}

\subsection{Microencapsulation with In Situ Polymerization}

In the in situ polymerization microencapsulation process, Citronella oil-Java (Sigma-Aldrich) was used as the core material, melamine-formaldehyde precondensate (Melamin, Kočevje, Slovenija) as the wall material and polyacrylic acid as the modifier (BASF, Ludwigshafen, Germany). All other used chemicals were laboratory grade. A laboratory reactor (Reactor-Ready, Radleys, Saffron Walden, UK) was equipped with a $1000 \mathrm{~mL}$ and $2000 \mathrm{~mL}$ vessel, a heating/cooling system and a Heidolph mixer (Heidolph overhead stirrer Hei-TORQUE 400, Heidolph Instruments, Schwabach, Germany) with the adjustable speed 0-2000 rpm. The microencapsulation process consisted of the following steps: (a) preparation of an aqueous solution of the modifier; (b) emulsification of citronella oil and formation of an oil-in-water emulsion; (c) addition of a melamine-formaldehyde precondensate; (d) induction of polymerisation by raising the temperature to $70-80^{\circ} \mathrm{C}$; (e) microcapsule formation at elevated temperature for $1 \mathrm{~h}$; and (f) termination of polymerization reaction with the addition of ammonia and sodium hydroxide, and cooling down to room temperature. The experiments without the core material were performed under the same conditions and the empty microcapsules were used as a blank in antimicrobial testing. The main process parameters are presented in Table 5. The size distribution measurement of microcapsules in the suspension was performed with a high-resolution laser granulometer (Mastersizer 2000, Malvern instruments Ltd., Malvern, England). 
Table 5. Main process parameters of citronella oil microencapsulation in situ polymerization.

\begin{tabular}{cc}
\hline Parameter & Value \\
\hline Filling & $400-1200 \mathrm{~mL}$ \\
Concentration of modifying agent & $4 \%-6.5 \%$ \\
Concentration of core material & $25 \%-40 \%$ \\
Concentration of wall material & $20-50 \mathrm{~g} / 100 \mathrm{~g}$ core material \\
Emulsification & $1600 \mathrm{rpm}, 30 \mathrm{~min}$, room $\mathrm{T}$ \\
Wall formation-polymerization & $1600 \mathrm{rpm}, 60 \mathrm{~min}, 70-80{ }^{\circ} \mathrm{C}$ \\
Diameter of microcapsules & $1-15 \mu \mathrm{m}$ \\
Microcapsule content in final suspension & $30 \%-45 \%$ \\
\hline
\end{tabular}

\subsection{Paper Coating with Microcapsule Suspensions}

The suspensions of citronella microcapsules were applied to paper surface by means of a lab-scale rod coater (K Control Coater, RK PrintCoat Instruments Ltd., Litlington, UK), ranging from 2 to $30 \mathrm{~g}$ of microcapsules per $\mathrm{m}^{2}$. Firstly, coating formulations similar to industrial processes were composed. Aqueous microcapsule suspensions from coacervation and from in situ processes were formulated with water-soluble starch or with carboxymethylcellulose (ratios 1:1 and 1:2), and coated on papers (label paper, $70 \mathrm{~g} / \mathrm{m}^{2}$, and paper for flexible packaging, $50 \mathrm{~g} / \mathrm{m}^{2}$ ) in the amount of $2 \mathrm{~g}$ formulation $/ \mathrm{m}^{2}$. Secondly, the water suspension of in situ microcapsules ( $43 \%$ dry weight) without any other additives was applied with a rod coater No. 8 on a $53 \mathrm{~g} / \mathrm{m}^{2}$ paper basis at the speed setting 4 . The coated sheets were dried in a lab dryer for $2 \mathrm{~min}$ at $110^{\circ} \mathrm{C}$. The maximum coating contained $30 \mathrm{~g}$ of dry microcapsules per $\mathrm{m}^{2}$ with optimum quality in terms of equal coat weight across the whole paper sheet.

\subsection{Pressure-Activation of Microcapsules-Weight Pulling Test}

The mechanical activation of coated papers containing citronella oil microcapsules was performed with weight pulling tests (Figures 2 and 3)-a modification of a smudging colouration test used in pressure-sensitive copying papers for the evaluation of the microcapsule wall resistance to mechanical stress [71]. Weights were pulled three times along the coated paper test specimens. A sterile $5 \mathrm{~kg}$ square shape weight was applied with three straight pulls for the visual evaluation of the mechanical activation of microcapsules, and in antimicrobial testing for the activation of coated papers in $140 \mathrm{~mm}$ Petri dishes (Deltalab, Barcelona, Spain) (cf. Figure 2). A sterile $3 \mathrm{~kg}$ weight in the form of a cylinder was used with three round pulls for the activation of microcapsules on coated papers in antimicrobial testing using standard $94 \mathrm{~mm}$ Petri dishes (Brand, Wertheim, Germany) (cf. Figure 3).

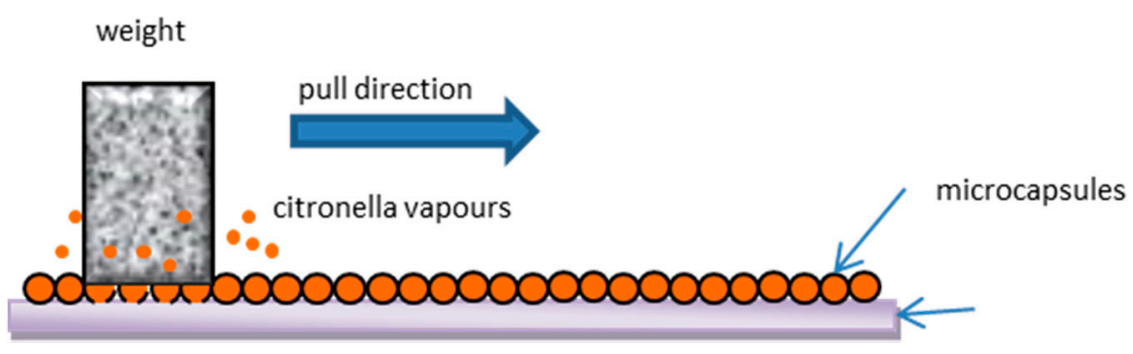

Figure 2. Mechanical activation of coated papers containing citronella oil microcapsules with weight pulling test. 


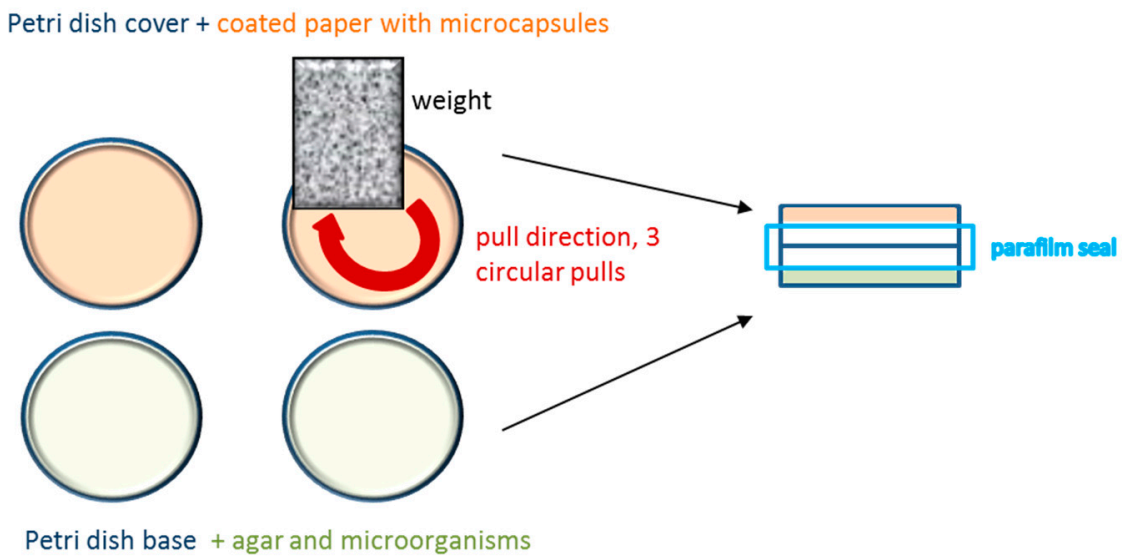

Figure 3. Mechanical activation of coated papers containing citronella oil microcapsules with weight pulling test before antimicrobial testing in Petri dishes.

\subsection{Morphology and Visualization of Microcapsules}

A transmission light microscope (TLM) (Bresser Researcher Trino 40-1000× with MicroCam, Bresser $\mathrm{GmbH}$, Rhede, Germany) was used for the visualisation of microcapsule formation during the microencapsulation process, and for the final aqueous suspensions of microcapsules. A scanning electron microscope (SEM) (JEOL JSM 6060LV, Tokyo, Japan) was used for the visualisation and morphological characterisation of microcapsules and coated papers. The samples were coated with an ultra-thin coating of carbon, gold and platinum with high vacuum evaporation. The observations were performed at $10 \mathrm{kV}$. Bright images of microcapsules were obtained.

\subsection{Determination of Minimum Inhibitory Concentrations (MIC) of Encapsulated and Non-Encapsulated Citronella Oil in Liquid Media}

The antimicrobial effects of free and microencapsulated citronella oil were determined as the minimum inhibitory concentration (MIC) in a liquid medium on Bacillus subtilis, Escherichia coli, Pseudomonas aeruginosa and Saccharomyces cerevisiae, with 2,3,5-triphenyltatrazolium chloride (TTC) added as an indicator. All MIC values were calculated according to the concentration of citronella oil in the microcapsule core. Microorganisms were cultivated on standard count agar, $37^{\circ} \mathrm{C}, 24 \mathrm{~h}$ (E. coli, S. aureus, B. subtilis) and Sabouraud $2 \%$ dextrose agar, $29^{\circ} \mathrm{C}, 24 \mathrm{~h}$ (S. cerevisiae). The samples of microorganisms were inoculated in the concentration $\sim 1 \times 10^{6} \mathrm{CFU} / \mathrm{mL}$. Six tubes, each with $8 \mathrm{~mL}$ of prepared microorganisms, were used for the addition of $2 \mathrm{~mL}$ of pure non-encapsulated or suspension of microencapsulated citronella oil, with the dilution system 1:4. For example, $2 \mathrm{~mL}$ of pure citronella oil ( $1 \%$ emulsion of citronella oil in water was used) were added to the first tube and mixed, then $2 \mathrm{~mL}$ from the first tube was added to the second tube and mixed, etc. The last tube was blank and used as a negative control. The colour indicator TTC $(1 \mathrm{~mL})$ was added into tubes, which were then immediately closed, mixed and incubated at $37^{\circ} \mathrm{C}$ (E. coli, S. aureus, B. subtilis) or $29^{\circ} \mathrm{C}$ (S. cerevisiae) in a dark place. In the case of live microorganisms, their dehydrogenases reduce the colourless TTC indicator into a red coloured triphenyl formazan. The results were observed as the colour change of samples after $24 \mathrm{~h}$. MIC was determined as the interval between the lowest concentration, where no colour developed, and the first concentration with a developed colour.

\subsection{Coated Papers Antimicrobial Activity Tests on Agar Plates in Petri Dishes}

The following protocol was developed and applied to evaluate the antimicrobial activity of citronella oil vapours released from the core of microcapsules in mechanically activated coated papers. The antimicrobial activity was tested on agar plates in 94 and $140 \mathrm{~mm}$ Petri dishes with E. coli 
(selected bacteria) and S. cerevisiae (selected yeast). E. coli was cultivated in the medium Standard count agar, $37^{\circ} \mathrm{C}, 24 \mathrm{~h}$, and S. cerevisiae on Sabouraud $2 \%$ dextrose agar, $29^{\circ} \mathrm{C}, 24 \mathrm{~h}$. After $24 \mathrm{~h}, 2 \mathrm{~mL}$ of Ringer solution was added. The inoculum $\sim 1 \times 10^{6} \mathrm{CFU} / \mathrm{mL}$ was diluted to the range of concentrations from $10^{5}$ to $10^{0}$. Due to the high overgrowth, the concentrations of microorganisms $\geq 10^{3} \mathrm{CFU} / \mathrm{mL}$ were too high to detect the effects. The concentrations of microorganisms $10^{2}$ and $10^{1} \mathrm{CFU} / \mathrm{mL}$ were found optimal to detect the activity of citronella oil vapours released from microcapsules in activated coated papers in Petri dishes. The prepared microorganism suspensions $(0.1 \mathrm{~mL})$ were put in a Petri dish. The samples of coated papers with microcapsules were circularly cut to fit the entire inside of the Petri dish cover. The paper coated with microcapsules, attached to the inner part of the Petri dish cover, was mechanically activated with a 3 or $5 \mathrm{~kg}$ weight with three circular pulls of the weight. The activation of microcapsules was performed just before the closure and the Petri dishes were then immediately sealed with parafilm (cf. Figure 3). The coated papers did not touch the agar plate. Mechanically activated microcapsules only released vapours of citronella oil into the atmosphere of the Petri dish, thus affecting the growth of microorganisms. For control, the tests were performed without the coated paper in a Petri dish. The results were evaluated after $24 \mathrm{~h}$ and $48 \mathrm{~h}$ of incubation. The tests were performed in triplicates for each sample.

\subsection{Statistical Analysis}

The results of antimicrobial testing performed in triplicates were statistically analysed and presented as a mean \pm standard deviation (SD). The $t$-test: two-sample assuming unequal variances was used to evaluate the differences in the antimicrobial activity between blank samples and samples containing papers with activated citronella oil microcapsules.

\section{Results and Discussion}

\subsection{Citronella Oil Microcapsules Produced with Complex Coacervation}

Microcapsules containing non-diluted citronella oil were successfully produced with complex coacervation in both combinations of wall materials, i.e., gelatine-carboxymethyl cellulose and gelatine-gum arabic. Microcapsules resulting from five different batches are presented in Figure 4. The container type structure with a liquid core and distinct thin elastic solid wall was evident with TLM. The microcapsule diameters ranged from 10 to $200 \mu \mathrm{m}$, depending on emulsification conditions and the addition of SDS emulsifier (cf. G-GA-7 and G-GA-9). Both wall hardening agents worked well, i.e., glutaraldehyde for covalent cross-linking (cf. G-CMC-1, G-GA-6, G-GA-7) and natural tannin for wall hardening via hydrogen bonds (cf. G-GA-8, G-GA-9). Microcapsule walls remained stable during air-drying and withstood vacuum conditions during the SEM microscopy.

The results are comparable with those from similar previous research, although there are no records in the available literature on the preparation of coacervate Cymbopogon citratus oil microcapsules in the same way and for the same purpose. Songkro et al. [63] prepared complex coacervation gelatine-acacia microcapsules of Cymbopogon winterianus oil for mosquito repellents. Magnetic stirrers were used, formaldehyde was employed as a hardening agent, the core-to-wall ratio was fixed to 1:2, and citronella oil dissolved in coconut oil was used. One of the findings was that citronella oil at $100 \%$ produced unstable microcapsules and the strength of microcapsule shells needed improvement. This problem seems to be resolved in our research (comparable batches G-GA-6 and G-GA-8), where stable microcapsules were prepared with $100 \%$ citronella oil and a high core-to-wall ratio (6:1) by using a powerful overhead stirrer with a turbine impeller, and glutaraldehyde or tannin wall hardening. The results of the batch G-GA-6 can also be compared with the research of Miro Specos et al. [55], who produced gelatine-gum arabic microcapsules of Cymbopogon nardus oil, cross-linked with glutaraldehyde, for mosquito repellent finishing of cotton textiles. Multi-core microcapsules with a blackberry-like morphology with diameters $25-100 \mu \mathrm{m}$ were obtained. Our microcapsules were single core and 50-200 $\mu \mathrm{m}$ in diameter, presumably due to different mixing conditions. While in our research, 
an overhead stirrer with a turbine impeller at $600 \mathrm{rpm}$ was used throughout the process, in the research above [55], a homogeniser at 18,500 rpm was used during emulsification, a pitched blade impeller during coacervation and a magnetic stirrer during hardening. This suggests that mixing conditions significantly affect the coacervation process and morphology of microcapsules.

\section{G-CMC-1}

gelatine-carboxymethyl cellulose wall, cross-linked with glutaraldehyde, no emulsifier

\section{G-GA-6}

gelatine-gum arabic wall, cross-linked with

glutaraldehyde, no emulsifier

\section{G-GA-7}

gelatine-carboxymethyl cellulose wall, cross-linked with glutaraldehyde, SDS emulsifier

\section{G-GA-8}

gelatine-gum arabic wall, treated with natural tannin, no emulsifier

G-GA-9 gelatine-gum arabic wall, treated with natural tannin, SDS emulsifier
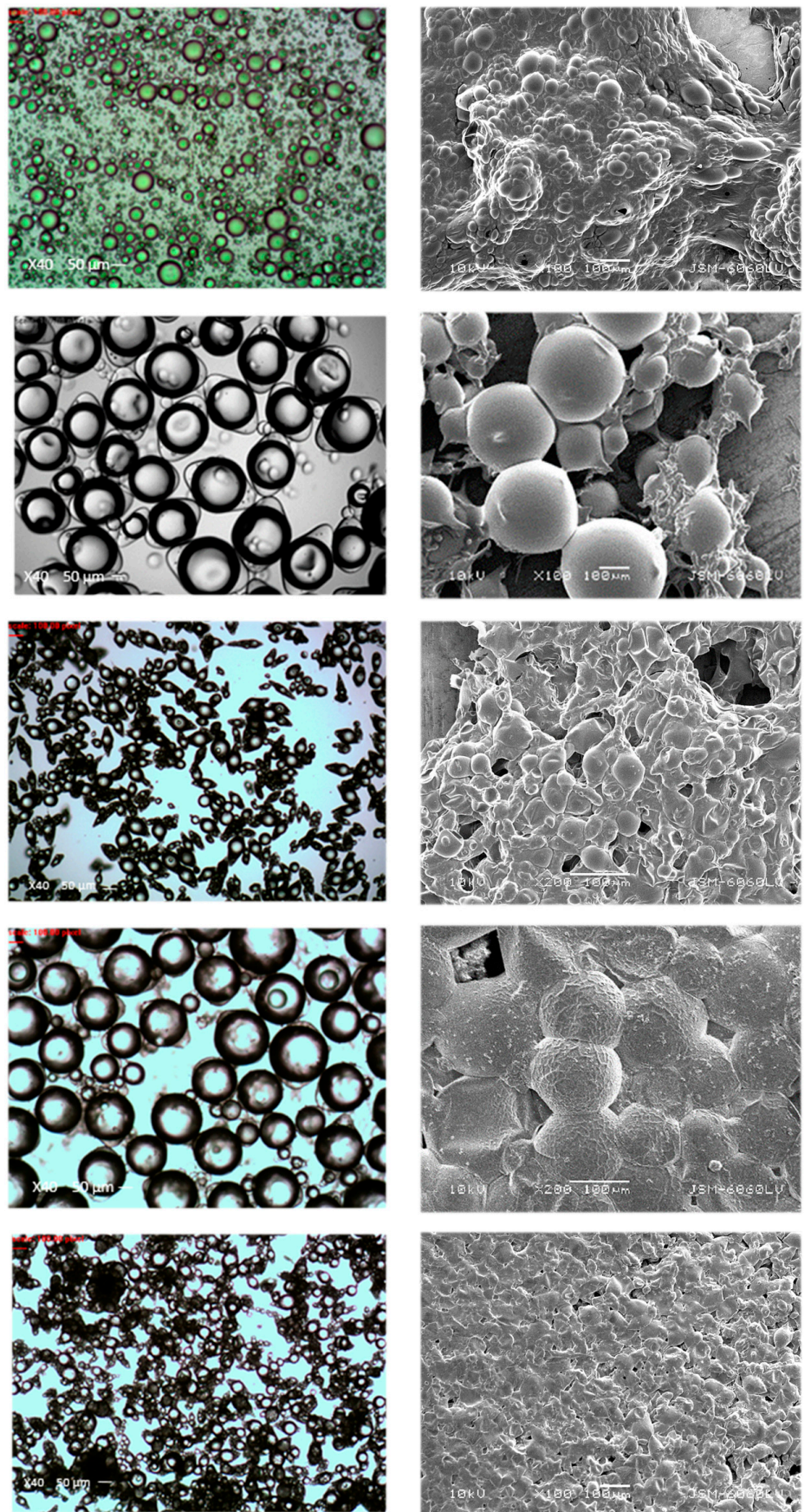

(a)

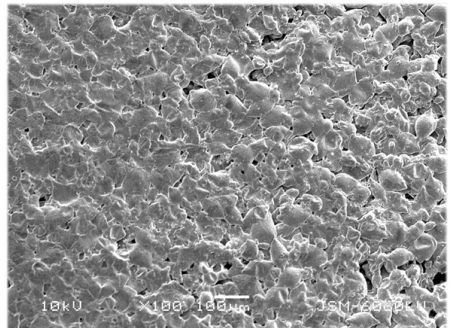

(b)

Figure 4. Comparison of five batches of citronella oil microcapsules produced with complex coacervation: (a) TLM of aqueous suspension (40×); (b) SEM of dry microcapsules $(100 \times, 200 \times)$.

For applications to textile carriers, researchers often used emulsifiers to achieve smaller dimensions of microcapsules. However, there seems to be no agreement about the best emulsifier for the citronella-gelatine-gum arabic coacervation system. Bezerra et al. [59] produced gelatine-gum arabic citronella microcapsules with 1-18 $\mu \mathrm{m}$ in diameter by applying sodium lauryl sulphate (SLS) emulsifier 
and glutaraldehyde for wall crosslinking. In our batches, G-GA-7 and G-GA-9, microcapsules of similar sizes and elongated ellipsoidal shapes were obtained by using SDS as an emulsifier. Liu et al. [57] reported on a successful preparation of $10 \mu \mathrm{m}$ citronella microcapsules with complex coacervation of gelatine and gum arabic, using Tween- 80 and Span- 80 emulsifiers, and glutaraldehyde for cross-linking. The microcapsules were formulated with 2D resin and grafted to cotton fabrics with the immersion method.

Regarding the replacement of glutaraldehyde cross-linking with tannins, the idea is not completely new, although it has been rarely used. Xing et al. [72] prepared gelatine-gum arabic capsaicin nanocapsules and treated them with hydrolysable tannins. According to their study, tannins had a protein precipitating ability due to the function of hydrogen bonding and hydrophobic effects and also influenced the morphology and nanoparticle dispersion. In our batches G-GA-8 and G-GA-9, tannins successfully replaced glutaraldehyde hardening. Thus, we obtained microcapsule suspensions containing only natural materials.

Microcapsule suspensions of all batches were homogeneous at the end of the microcapsule production process. However, with days and weeks of storage, the suspensions of gelatine-carboxymethyl cellulose microcapsules became viscous and slightly gelled throughout the continuous phase. The gelatine-gum arabic microcapsule suspensions did not show any increased viscosity; however, a layering process occurred with ageing, with larger citronella oil microcapsules floating at the top and smaller microcapsules being gathered at the bottom. It is therefore recommended that freshly prepared coacervation microcapsule suspensions are used for paper coating.

\subsection{Citronella Oil Microcapsules Produced with in Situ Polymerization}

Citronella oil was successfully microencapsulated with the in situ polymerisation method. The properties of in situ microcapsule suspensions are summarized in Table 6. Compared to coacervation microcapsules, the in situ citronella microcapsules were smaller and had spherical rigid walls with a smooth surface (cf. Figure 5). This observation is in accordance with Sun and Zhang [73], who compared the mechanical strengths of in situ and coacervation microcapsules with the micromanipulation technique, and found out that in situ microcapsules showed viscoelastic behaviour at small deformations, plastic at relatively large deformations, and had a clear bursting under compression, while the coacervation microcapsules showed elastic behaviour and did not show clear bursting under compression. Their findings coincide with our observations of microcapsule activation with the weight pulling test, where compression and shear forces were needed for a successful activation to release citronella oil. An important role in the activation of microcapsules is played also by their size, which can be adjusted with process parameters [74,75]. According to the particle size distribution measurements, the average size of our in situ microcapsules containing citronella oil was $6 \mu \mathrm{m}$, with the range 1-15 $\mu \mathrm{m}$ (cf. Figure 6). Sizes and morphology of produced microcapsules were similar to those done by Chung et al. [76], who used the in situ polymerization technology to prepare microcapsules with thyme oil for an insect repellent in food packaging.

Table 6. Properties of microcapsules produced with in situ polymerization.

\begin{tabular}{cc}
\hline Parameter & Value \\
\hline Appearance & white suspension \\
Microcapsule content & $43 \%$ \\
Wall material & Melamine-formaldehyde resin \\
Core material & Pure citronella oil \\
Microcapsule size & $1-15 \mu \mathrm{m}$ \\
$\mathrm{pH}$ & $6-7.5$ \\
Viscosity & $200-400 \mathrm{MPa}$ s \\
Microencapsulation efficiency & more than $95 \%$ \\
\hline
\end{tabular}




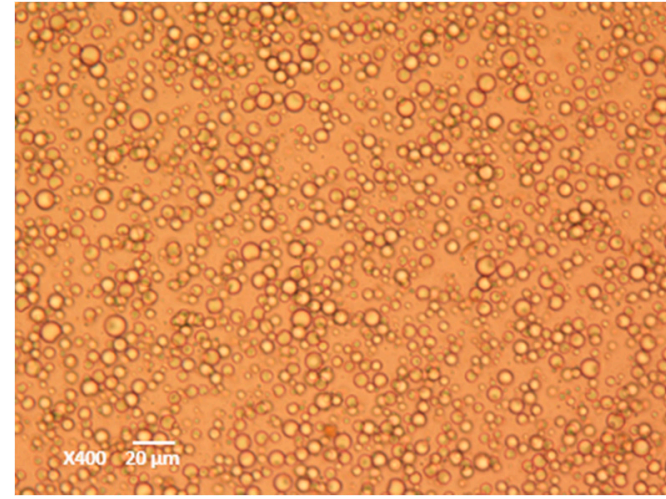

(a)

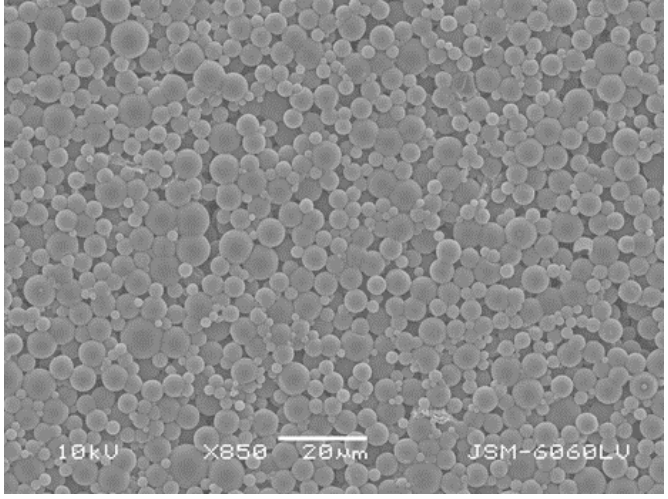

(b)

Figure 5. Citronella oil microcapsules produced with in situ polymerization: (a) aqueous suspension of microcapsules at end of polymerization process (TLM, 400×); (b) SEM of dry microcapsules (850×).

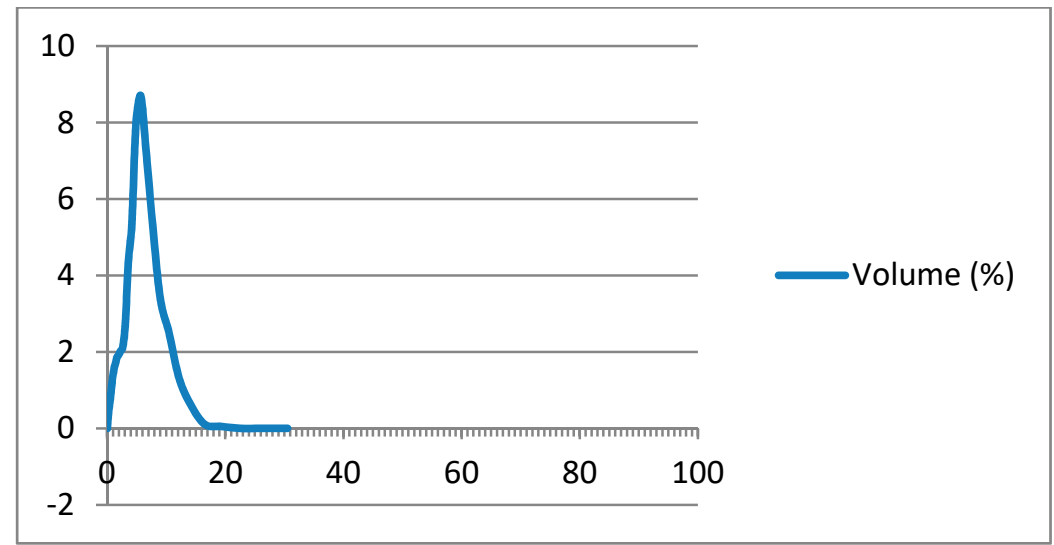

Figure 6. In situ microcapsule size distribution by volume (\%).

The in situ microcapsule suspensions were homogeneous at the end of the production process and stable for days and weeks. After the six-month storage at room temperature, the in situ microcapsules slowly accumulated in a layer on the surface, but were easily re-mixed and their morphology did not change. It is assumed that the shelf life could be at least 2 years, which is in accordance with the results of the time-release analysis done by Zhao et al. [77], who calculated 1.65 years as the theoretical storage time.

\subsection{Coated Papers}

Both types of microcapsules were tested and used in paper coatings (cf. Figure 7). Coacervation microcapsules demonstrated some deficiencies during the coating-suspensions were prone to agglomeration and larger particles were removed by the coating rod during the coating process. In consequence, due to smaller dimensions (below $10 \mu \mathrm{m}$ ), superior suspension stability and formulation mixing, the in situ polymerization citronella oil microcapsules were selected as a priority for paper coatings in industrial settings. With the maximum achieved coating weight $\left(30 \mathrm{~g} / \mathrm{m}^{2}\right)$ on paper, even without any binders added, the adherence of in situ microcapsules to paper was surprisingly good, with superior quality in terms of equal coat weight across the whole paper sheet. 


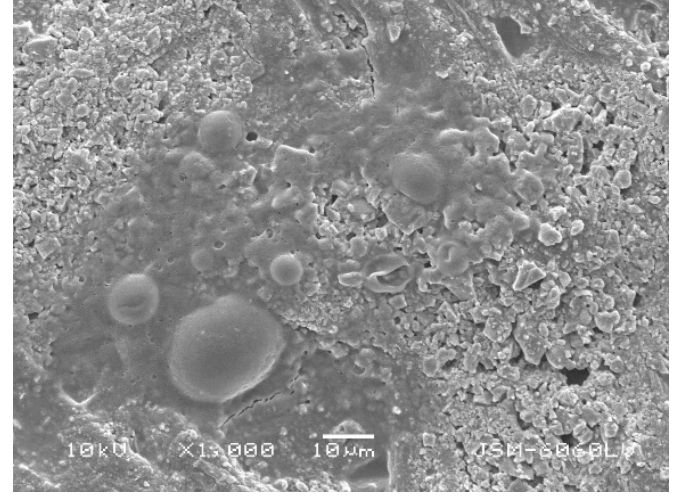

(a)

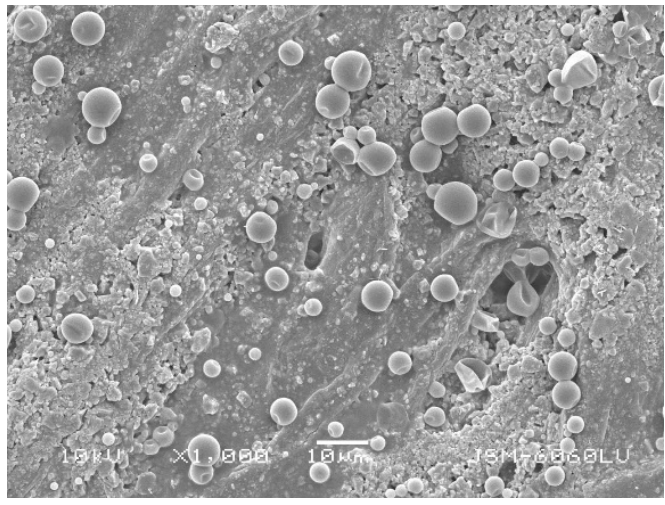

(b)

Figure 7. Paper coated with a formulation containing microcapsules $\left(2 \mathrm{~g} / \mathrm{m}^{2}\right)$ : (a) coacervation microcapsules (SEM, 1000×); (b) in situ polymerization microcapsules (SEM, 1000×).

\subsection{Mechanical Activation of Microcapsules on Paper}

The SEM photomicrographs of microcapsules activated by mechanical pressure confirmed the pressure-activation mechanism by rupturing microcapsule walls of both, coacervation and in situ, citronella microcapsules (cf. Figure 8).

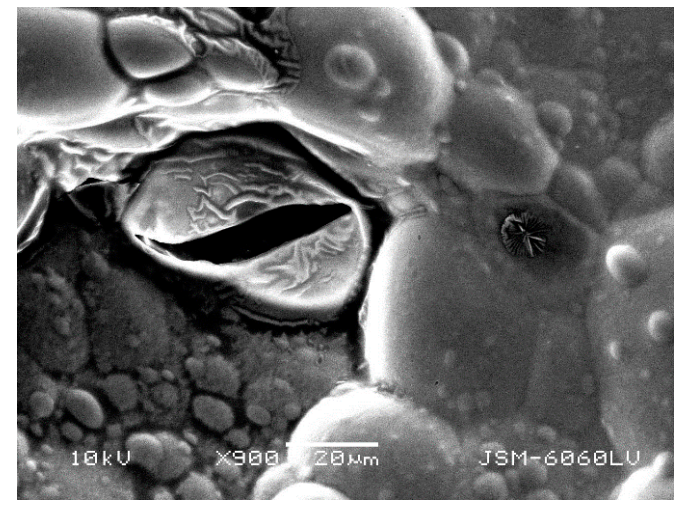

(a)

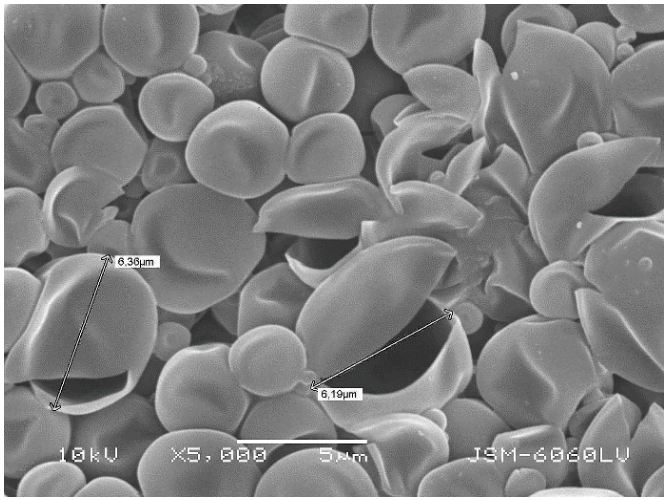

(b)

Figure 8. Pressure-activated citronella oil microcapsules: (a) produced with complex coacervation (SEM, 900×); (b) produced with in situ polymerization (SEM, 5000×).

Furthermore, the SEM morphological characterisation of papers coated with formulations containing in situ polymerization citronella microcapsules activated with the $5 \mathrm{~kg}$ weight pulling test revealed a partial pressure-activation of in situ polymerization microcapsules-some microcapsules with broken walls and empty cores were visible, while others remained intact (cf. Figures 9 and 10). This indicated that not all essential oil was released from microcapsules at once and suggested the possibility of prolonged use, with the gradual release of citronella oil at multiple exposures to pressure.

The results suggested that the mechanism of citronella oil release by mechanical pressure was suitable for the intended application. Nevertheless, the question remained whether the amount of released citronella oil is sufficient to achieve the antimicrobial effect. 


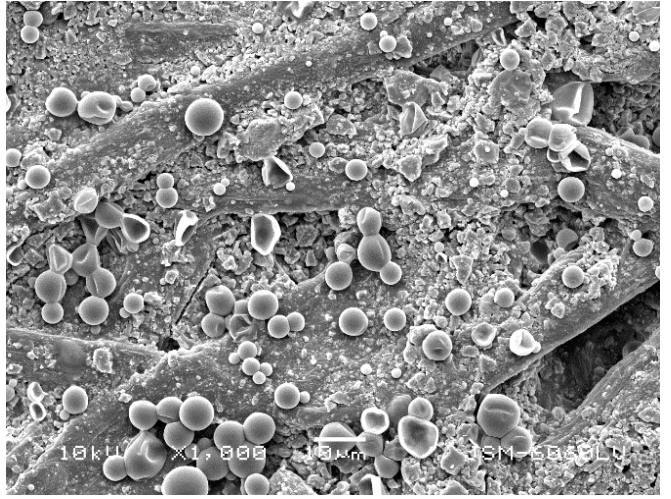

(a)

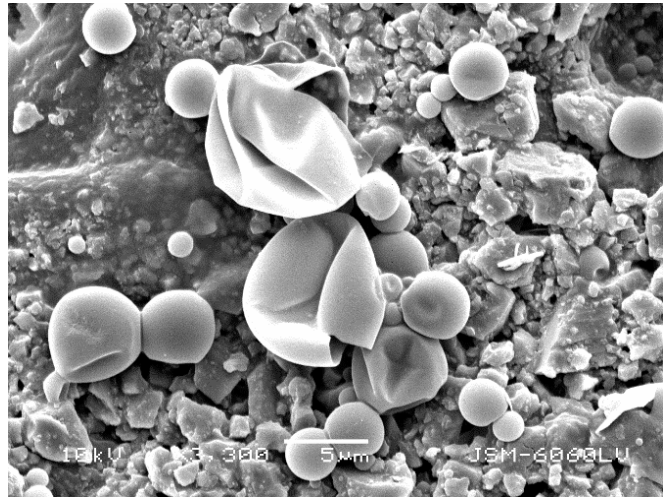

(b)

Figure 9. Coated paper with in situ polymerization microcapsules (coating $2 \mathrm{~g} / \mathrm{m}^{2}$ ), after $5 \mathrm{~kg}$ weight pulling test: (a) SEM 1000×; (b) SEM 3300×.

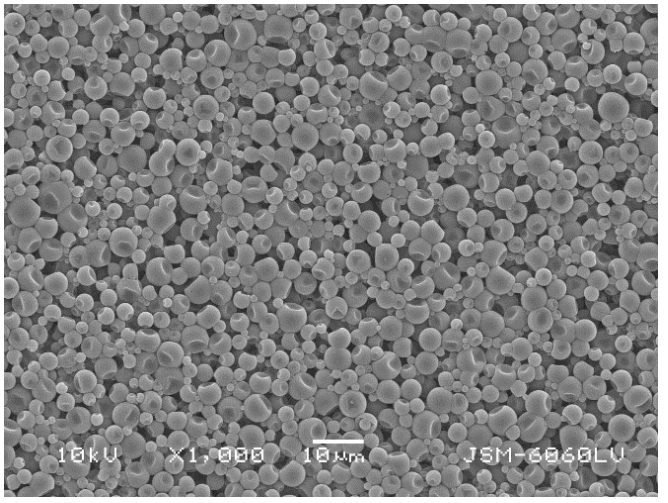

(a)

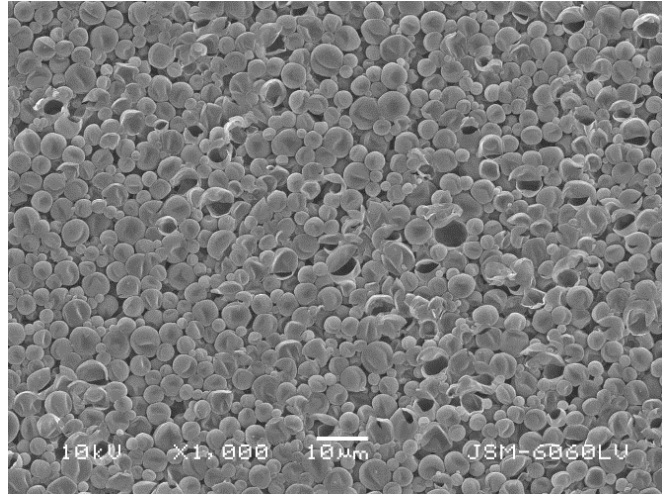

(b)

Figure 10. Maximum coating of in situ microcapsules on paper (coating $30 \mathrm{~g} / \mathrm{m}^{2}$ ) with no binders added: (a) non-activated; (b) after $5 \mathrm{~kg}$ weight pulling test.

\subsection{Antimicrobial Activity}

\subsubsection{MIC of Non-Encapsulated and Microencapsulated Citronella Oil}

The MIC values of the antimicrobial testing of citronella oil, non-activated coacervation microcapsules and in situ microcapsules in a liquid medium collected after $24 \mathrm{~h}$ of incubation are presented in Table 7. To exclude potential influences of other chemicals used in the microencapsulation process, empty microcapsules were also prepared without the citronella oil core and used as a blank in antimicrobial testing.

For the non-activated coacervation microcapsules with citronella oil, the MIC values were detected within the range $0.07 \%<$ MIC $>0.014 \%$ for bacterial species B. subtilis, E. coli, P. aeruginosa, while for the yeast S. cerevisiae, a higher value, $1.72 \%<$ MIC $>0.34 \%$, was determined. Empty coacervation microcapsules without the citronella core (blank) caused no inhibition on E. coli and S. cerevisiae, or a higher MIC $>1.72 \%$ was detected with $B$. subtilis and P. aeruginosa, possibly due to some glutaraldehyde remains in the suspension. The observed antimicrobial activity of the citronella oil coacervation microcapsules can be attributed to partially permeable walls, releasing the core substance. The obtained MIC values are comparable to the results by Wang et al. [66], who produced citronella oil microcapsules with hydroxyapatite/quaternary ammonium salt of chitosan/sodium alginate walls, and determined MIC $0.0625 \%$ for E. coli and S. aureus. For E. coli and B. subtilis, the results also coincide with literature data for the non-capsulated citronella oil-MIC $0.06 \%$ was determined by Naik et al. [70]. 
Table 7. MIC determination of free and microencapsulated citronella oil.

\begin{tabular}{cccccc}
\hline Microorganism & $\begin{array}{c}\text { Non-Encapsulated } \\
\text { Citronella Oil }\end{array}$ & $\begin{array}{c}\text { Coacervation } \\
\text { Microcapsules with } \\
\text { Citronella Oil }\end{array}$ & $\begin{array}{c}\text { Coacervation } \\
\text { Microcapsules } \\
\text { without Core }\end{array}$ & $\begin{array}{c}\text { in situ } \\
\text { Microcapsules with } \\
\text { Citronella Oil }\end{array}$ & $\begin{array}{c}\text { in situ } \\
\text { Microcapsules } \\
\text { without Core }\end{array}$ \\
\hline E. coli & $0.2 \%<$ MIC $>0.04 \%$ & $0.07 \%<$ MIC $>0.014 \%$ & no inhibition & MIC $>1.72 \%$ & no inhibition \\
P. aeruginosa & MIC $>0.11 \%$ & $0.07 \%<$ MIC $>0.014 \%$ & MIC $>1.72 \%$ & MIC $>1.72 \%$ & no inhibition \\
B. subtilis & $0.2 \%<$ MIC $>0.04 \%$ & $0.07 \%<$ MIC $>0.014 \%$ & MIC $>1.72 \%$ & $1.72 \%<$ MIC $>0.34 \%$ & MIC $>1.72 \%$ \\
S. cerevisiae & MIC $>0.2 \%$ & $1.72 \%<$ MIC $>0.34 \%$ & no inhibition & MIC $>1.72 \%$ & no inhibition \\
\hline
\end{tabular}

In contrast, in the case of non-activated in situ polymerization microcapsules, the range $1.72 \%<$ MIC $>0.34 \%$ was determined for B. subtilis, and MIC $>1.72 \%$ for E. coli, P. aeruginosa and S. cerevisiae. Empty in situ microcapsules without the citronella core (blank) caused no inhibition on E. coli, P. aeruginosa and S. cerevisiae. With B. subtilis, a higher MIC $>1.72 \%$ was determined, presumably due to some traces of formaldehyde in the suspension. The results suggested that the in situ polymerization microcapsule walls were impermeable and that no residual non-encapsulated citronella oil was present in the suspension.

For non-encapsulated citronella oil, the range $0.2 \%<\mathrm{MIC}>0.04 \%$ was determined for E. coli and B. subtilis, while for S. cerevisiae MIC $>0.2 \%$ and for P. aeruginosa MIC $>0.11 \%$ were observed. It is known that the antimicrobial testing of non-encapsulated oil in aqueous systems is problematic due to its water insolubility. In addition, citronella oil is composed of several substances with different solubility factors and different activities. In the preparation of samples and during antimicrobial testing, the separation of oil and water phases occurs. Therefore, microorganisms in aqueous media are in limited contact with the oil. Consequently, the higher MIC, determined for non-encapsulated citronella oil, in comparison with some results of microencapsulated citronella oil may be attributed to the fact that in partially permeable microcapsules, the active ingredient is more homogeneously distributed through the whole liquid media. This observation is also in alignment with Donsi et al. [78], who noticed that the antimicrobial activity of essential oils was limited by their solubility and availability for interaction with microorganism cells.

\subsubsection{Antimicrobial Activity of Coated Papers}

Two series of coated papers were used in antimicrobial testing, i.e., minimum coatings of $2 \mathrm{~g} / \mathrm{m}^{2}$ and maximum coatings of $30 \mathrm{~g} / \mathrm{m}^{2}$. In the case of $2 \mathrm{~g}$ of applied coating formulation $/ \mathrm{m}^{2}$ of paper, the determination of aerobic mesophilic bacteria on Standard count agar (for E. coli, P. aeruginosa, B. subtilis) and determination of yeast on Sabouraud $2 \%$ glucose agar (for S. cerevisiae) revealed no significant difference between the uncoated paper matrices and papers coated with the formulation containing in situ polymerization microcapsules with citronella, without or with pressure-activation. The result could be expected, as the $2 \mathrm{~g} / \mathrm{m}^{2}$ coating only contained approximately $1.44 \mathrm{~g}$ of encapsulated citronella oil per $\mathrm{m}^{2}$. Furthermore, according to the protocol, the $1 \mathrm{~cm}^{2}$ testing sample on agar plate contained only $1.4 \times 10^{-4} \mathrm{~g}$ of citronella oil in microcapsules.

In the second part of the research, the maximum coating of $30 \mathrm{~g} / \mathrm{m}^{2}$ with in situ microcapsules were used and the coated paper of the whole Petri dish cover size was applied in the protocol. 140 and $94 \mathrm{~mm}$ Petri dishes were used. The samples were activated with a weight pulling test, which opened a part of microcapsules, and the results were compared to blank Petri dishes with no paper added. The calculation shows that if all microcapsules had been opened, the $30 \mathrm{~g} / \mathrm{m}^{2}$ coated paper would have released $0.13137 \mathrm{~g}$ of citronella oil from the in situ microcapsules cores in the $94 \mathrm{~mm}$ Petri dish, and $0.32307 \mathrm{~g}$ in the $140 \mathrm{~mm}$ Petri dish.

In all blank samples, microbial growth was observed already after $24 \mathrm{~h}$ of incubation.

In the experiments with coated papers in $140 \mathrm{~mm}$ Petri dishes, no microorganism growth was observed either after 24 or $48 \mathrm{~h}$ of incubation. This suggested that the concentration of citronella oil vapours released from the activated paper coating was sufficient for the total inhibition of microorganisms, and the antimicrobial activity of $30 \mathrm{~g} / \mathrm{m}^{2}$ coated papers was confirmed for both tested 
microorganisms, i.e., E. coli and S. cerevisiae. An example of antimicrobial testing results for S. cerevisiae after $48 \mathrm{~h}$ of incubation is presented in Figure 11.

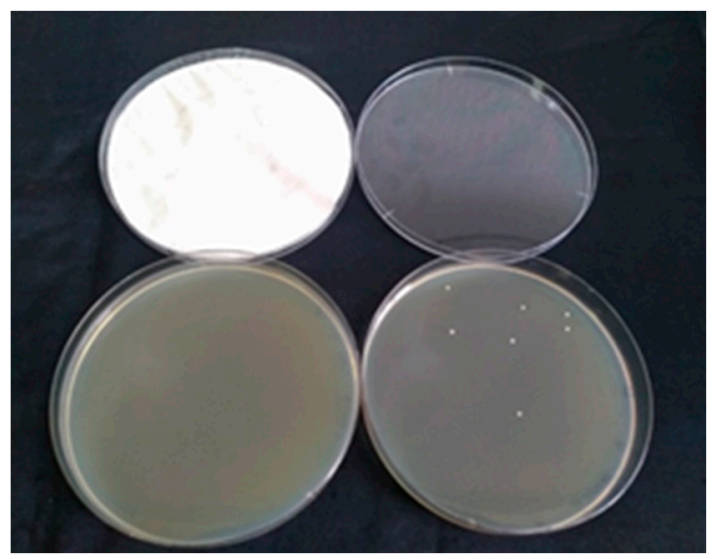

(a)

(b)

Figure 11. Example of antimicrobial testing results for S. cerevisiae after $48 \mathrm{~h}$ of incubation: (a) $30 \mathrm{~g} / \mathrm{m}^{2}$ paper coating of in situ microcapsules with citronella oil, activated by $5 \mathrm{~kg}$ weight in $140 \mathrm{~mm}$ Petri dish; (b) blank sample without coated paper.

In the experiments with coated papers in $94 \mathrm{~mm}$ Petri dishes, there was no growth in the samples with activated coated papers after $24 \mathrm{~h}$ of incubation for either tested microorganisms, E. coli or S. cerevisiae. After $48 \mathrm{~h}$ of incubation, microorganism growth occurred, but substantially smaller with E. coli than with S. cerevisiae (cf. Table 8), which indicated their different susceptibility or resistance to citronella oil components. According to the statistical evaluation using the $t$-test, two-sample assuming unequal variances, a significant difference in the antimicrobial activity was confirmed between blank samples and samples with papers coated with activated citronella microcapsules in all cases after $24 \mathrm{~h}$ of incubation ( $p$ two-tail $<0.05$ ). After $48 \mathrm{~h}$ of incubation, the difference was statistically significant in all but two cases (S. cerevisiae $10^{2}$ and E. coli $10^{1}$ ).

Table 8. Antimicrobial activity (number of colonies, CFU/Petri dish) of E. coli and S. cerevisiae after 24 and $48 \mathrm{~h}$ (average of 3 parallels), paper coating $30 \mathrm{~g} / \mathrm{m}^{2}, 94 \mathrm{~mm}$ Petri dish, activation by $3 \mathrm{~kg}$ weight, three pulls.

\begin{tabular}{ccccccccc}
\hline & \multicolumn{4}{c}{ Blank Samples (CFU/plate) } & \multicolumn{3}{c}{ Samples with Activated Paper (CFU/plate) } \\
\cline { 2 - 9 } Time & E.coli & E.coli & S. cerevisiae & S. cerevisiae & E. coli & E. coli & S. cerevisiae & S. cerevisiae \\
$\mathbf{1 0}^{\mathbf{2}}$ & $\mathbf{1 0}^{\mathbf{1}}$ & $\mathbf{1 0}^{\mathbf{2}}$ & $\mathbf{1 0}^{\mathbf{1}}$ & $\mathbf{1 0}^{\mathbf{2}}$ & $\mathbf{1 0}^{\mathbf{1}}$ & $\mathbf{1 0}^{\mathbf{2}}$ & $\mathbf{1 0}^{\mathbf{1}}$ \\
\hline $24 \mathrm{~h}$ & $58 \pm 7.3$ & $2.7 \pm 0.9$ & $46 \pm 6.5$ & $8.3 \pm 2.1$ & 0 & 0 & 0 & 0 \\
$48 \mathrm{~h}$ & $87 \pm 45$ & $2.7 \pm 0.9$ & $61.7 \pm 5.9$ & $8.3 \pm 2.1$ & $5.3 \pm 3.1$ & $0.3 \pm 0.5$ & $41.3 \pm 10.3$ & $2.7 \pm 1.7$ \\
\hline
\end{tabular}

\section{Conclusions}

The research project aimed to develop a pressure-sensitive controlled-release microencapsulated form of a natural antimicrobial agent, which could be used as a functional additive in food or pharmaceutical secondary packaging products made of paper or cardboard. In a series of research steps, presented in Figure 12, this aim was successfully achieved.

The essential oil of Cymbopogon citratus (citronella oil), known for its antimicrobial properties and pleasant aroma, was selected as the priority active compound. Due to its lipophilic nature and high volatility, citronella oil was microencapsulated with two alternative methods, i.e., complex coacervation of gelatine in combination with carboxymethylcellulose or gum arabic, and with in situ polymerization of melamine-formaldehyde prepolymers with a polyacrylic acid modifier. Both microencapsulation methods were successful and resulted in a container type microcapsules with a distinct liquid core and 
solid wall. The coacervate microcapsules were larger, with elastic natural polymer walls and partial permeability, while the in situ polymerization microcapsules were smaller, with spherical, rigid and impermeable pressure-sensitive synthetic polymer walls.

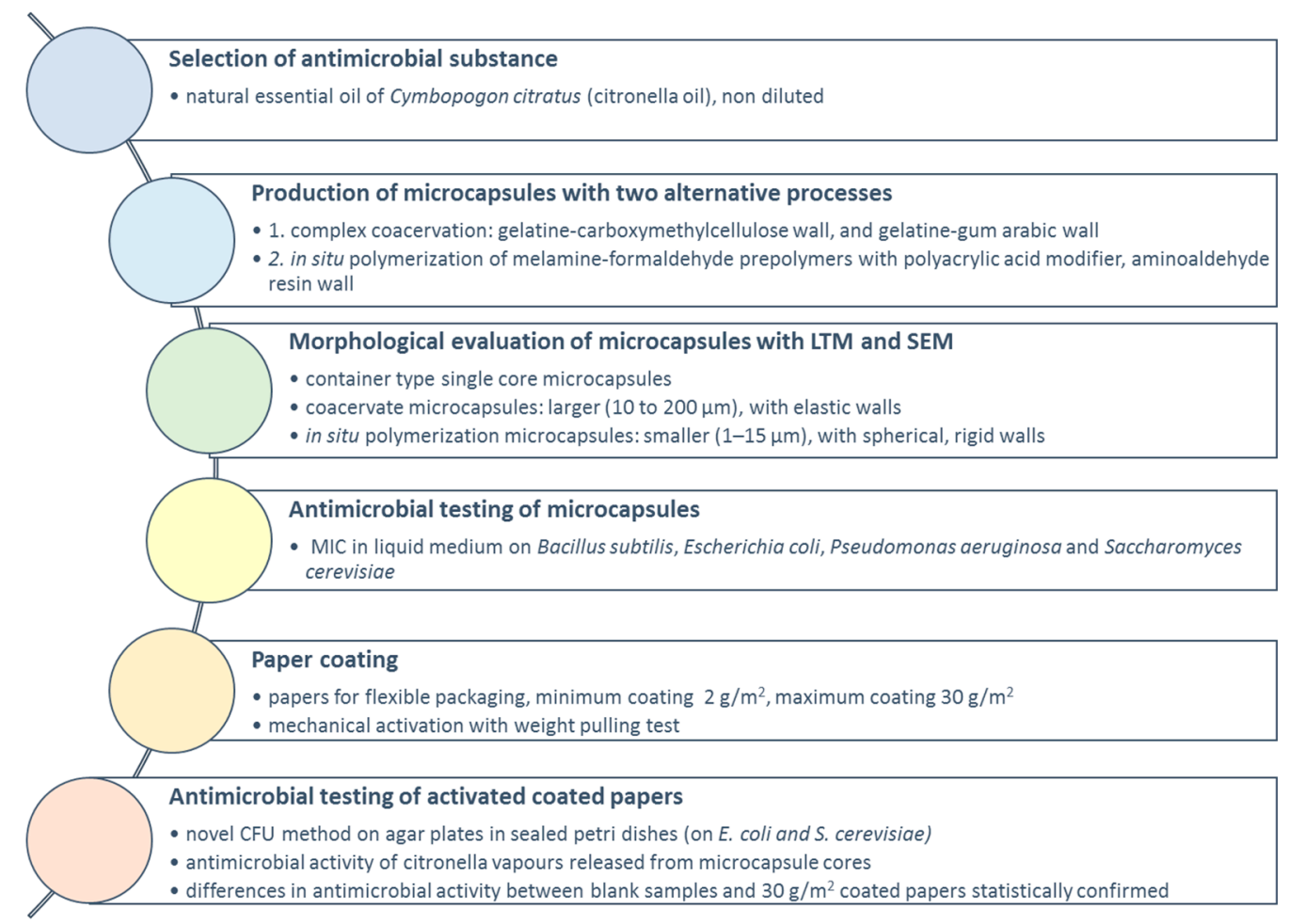

Figure 12. Outline of research flow.

Aqueous microcapsule suspensions were formulated with water soluble binders or were used directly for paper coatings. The suspensions of in situ microcapsules were chosen as a priority candidate for paper coatings in industrial settings since the in situ process was robust, the suspensions were homogeneous, showed good storage stability, formulation compatibility, small microcapsule dimensions (preferably below $10 \mu \mathrm{m}$ ), no aggregation and excellent coating properties. The suspensions of gelatine-carboxymethyl cellulose coacervation microcapsules tended to become viscous and gelled with time, and the gelatine-gum arabic microcapsule suspensions were prone to layering. Hence, the coacervation microcapsule suspensions should be used freshly prepared. In packaging applications, where only natural materials are preferred, gelatine-gum arabic citronella oil microcapsules hardened with tannin seem to be the preferred choice.

The antimicrobial testing in liquid media confirmed the antimicrobial activity (MIC) of non-encapsulated citronella oil and of citronella coacervation microcapsules, while for the non-activated in situ citronella microcapsules, MIC was due to impermeable microcapsule walls not detected.

The maximum achieved paper coating contained $30 \mathrm{~g} / \mathrm{m}^{2}$ of in situ citronella oil microcapsules with no binders added. Pressure-sensitive microcapsules were activated with a metal weight test and the SEM characterisation after three pulls revealed that some microcapsules released the core, whereas others remained intact. This suggested the possibility of prolonged product use, with gradual release of citronella oil at multiple exposures of functional papers to pressure, e.g., by a human hand during product handling.

Coacervate citronella oil microcapsules have partially permeable walls and could be more suitable for applications with the gradual release of the essential oil without a mechanical activation, while the in situ polymerization microcapsules are impermeable and appropriate for products where long-term retention is desired, and the release of the active substance by mechanical pressure is planned. It can 
be speculated that the combination of both microcapsule types could have a combined effect- the slow sustained release of citronella oil, and planned quick pressure-activated release when used after prolonged storage.

A new protocol was developed to test the antimicrobial activity of activated coated papers containing pressure-sensitive citronella oil microcapsules. Citronella oil vapours released after the mechanical activation from microcapsule cores into the sealed Petri dish successfully inhibited the growth of microorganisms under experimental conditions. According to our best knowledge, this is the first description of the experimental setting to test and prove the antimicrobial activity of released vapours from microcapsule cores in pressure-sensitive antimicrobial papers.

Author Contributions: Conceptualization, B.Š. (Boštjan Šumiga), B.Š. (Barbara Šumiga), D.R. and B.B.P.; Methodology, B.̌̌. (Boštjan Šumiga), B.Š. (Barbara Šumiga), and B.B.P.; Software, B.Š. (Boštjan Šumiga) and B.B.P.; Validation, B.Š. (Boštjan Šumiga), B.Šs. (Barbara Šumiga), D.R. and B.B.P.; Formal Analysis, B.Š. (Boštjan Šumiga), B.Š. (Barbara Šumiga), and B.B.P.; Investigation, B.Š. (Boštjan Šumiga), B.Š. (Barbara Šumiga), and B.B.P.; Resources, B.Š. (Boštjan Šumiga), B.Š. (Barbara Šumiga), D.R. and B.B.P.; Data Curation, B.Š. (Boštjan Šumiga), B.Š. (Barbara Šumiga), and B.B.P.; Writing—Original Draft Preparation, B.Š. (Boštjan Šumiga), B.Š. (Barbara Šumiga), D.R. and B.B.P.; Writing-Review and Editing, B.Š. (Boštjan Šumiga) and B.B.P; Visualization, B.Š. (Boštjan Šumiga) and B.B.P.; Supervision B.B.P.; Project Administration, B.B.P.; Funding Acquisition, D.R. and B.B.P.

Funding: This research was funded by the Republic of Slovenia, Ministry of Education, Science and Sport, and the European Union under the European Regional Development Fund (2016-2020), and RDI project Cel.Cycle: "Potential of biomass for development of advanced materials and bio-based products" (OP20.00365).

Conflicts of Interest: The authors declare no conflict of interest. The funders had no role in the design of the study, in the collection, analyses or interpretation of data, in the writing of the manuscript, or in the decision to publish the results.

\section{References}

1. Arshady, R. Microspheres Microcapsules Liposomes: Preparation Chemical Applications; Citus Reference Series, MML Series; Citus Books: London, UK, 1999; p. 576.

2. Ghosh, S.K. Functional Coatings: By Polymer Microencapsulation; Wiley-VCH: Weinheim, Germany, 2006; p. 357.

3. Benita, S. Microencapsulation: Methods and Industrial Applications, 2nd ed.; Taylor \& Francis: New York, NY, USA, 2006; p. 781.

4. Miller, R.E.; Brown, R.W. Pressure-Sensitive Record Material. U.S. Patent US4675706A, 23 June 1987.

5. Kukovič, M. Tiskarska Brezsajna Kopirna Barva. Slovenia Patent SI9300539A, 30 April 1995.

6. Junji, H.; Takaaki, K.; Sukeharu, W. Self-Color Forming Pressure- and Heat-Sensitive Recording Sheet. Japan Patent JP10264516A, 4 April 1998.

7. Satoshi, N. Pressure Sensitive Fluorescent Complex. Japan Patent JP11198527A, 27 July 1999.

8. Hirasawa, A.; Naoi, S. Back Carbon Ink, and Tamperproof Pressure-Sensitive Copying Sheet Using the Same. Japan Patent JP2002129077A, 9 May 2002.

9. Kukovič, M.; Knez, E. Postopek Priprave Nosilcev, Impregniranih ali Premazanih z Mikrokapsuliranimi Dišavami. Slovenia Patent SI9400362A, 30 April 1996.

10. Watanabe, M.; Watanabe, Y.; Kawasaki, K.; Ogawa, A.; Yoshimatsu, T.; Kato, S.; Otohata, T. Printing Paper Containing Microcapsules of Oily Substances. Japan Patent JP2014169512A, 18 Spetember 2014.

11. Fan, Y.; Fengchun, J.; Xiaobo, X.; Na, W.; Huqi, T. Cigarette Paper. China Patent CN103362033A, 23 October 2013.

12. Eom, J.K. Printing Paper Capable of Emitting Natural Aroma. Korea Patent KR791060B, 3 January 2008.

13. Hirata, N. Method of Producing Scented Tissue Paper Product. U.S. Patent US20170175336A1, 22 June 2017.

14. Dong, C.; Liu, Y.; Long, Z.; Pang, Z.; Yunhui, L.; Li, X. Effect of papermaking conditions on the retention of reversible thermochromic microcapsule in paper. BioResources 2011, 7, 66-77.

15. Li, X.; Zhang, N.; Sun, S.; Lai, W.; Fu, G. Imaging Method and Printer Applaying Photo-Thermal Sensitive Material. China Patent CN101020394A, 22 August 2007.

16. Lewis, M.W.; Rosenbaum, J.C.; Herbert, A.J.; Attri, P. Microsencapsulated System for Thermal Paper. U.S. Patent US5741592A, 21 April 1998. 
17. Li, J.; Zou, J.; Xiao, H.; He, B.; Hou, X.; Qian, L. Preparation of novel nano-sized hydrogel microcapsules via layer-by-layer assembly as delivery vehicles for drugs onto hygiene paper. Polymers 2018, 10, 335. [CrossRef] [PubMed]

18. Romano, V. Disposable Paper Sheet Comprising a Antimicrobial and Antibacterial Substance and Its Method of Manufacture. European Patent EP2583593A1, 24 April 2013.

19. Nanbu, Y.; Ujii, M. Foamed Wallpaper. Japan Patent JP2018066089A, 26 April 2018.

20. Jayet Laraffe, C.; Rosset, H. Information Carrier Having Biocidal Properties and Method of Manufacturing the Same. France Patent FR2838025A1, 10 October 2003.

21. Hamu, S.; Takeuchi, T. Antibacterial Regenerated Artificial Leather Paper. Japan Patent JPH11172581A, 29 June 1999.

22. Watanabe, N. Wiping Papers and Their Manufacture. Japan Patent JP06125862A, 10 May 1994.

23. Fan, Y. Antimicrobial Waterproofing Paper, and Preparation Method Thereof. China Patent CN107780306A, 9 March 2018.

24. Li, Y.; Lei, Y.; Wei, L. Preparation Method of Color-Developing Antimicrobial Sucrose Wrapping Paper. China Patent CN107604752A, 19 January 2018.

25. Singh, S.; Gaikwad, K.K.; Lee, M.; Lee, Y.S. Microwave-assisted micro-encapsulation of phase change material using zein for smart food packaging applications. J. Therm. Anal. Calorim. 2018, 131, 2187-2195. [CrossRef]

26. Li, L. Preparation Method of Environment-Friendly Antibacterial Antioxidative Packaging Paper. China Patent CN108716166A, 30 October 2018.

27. Merino Ciudad, J. Smart Container for Food and Fluids. Patent WO2016128594A, 18 August 2016.

28. Ko, G.S. Manufacturing Method of Raw Material Paper of Packaging Box for Agricultural Products for Extending Storage Expiration Date. Korea Patent KR1771353B, 24 August 2017.

29. Wang, S.; Zhang, X. Medical Heat-Sensitive Paper. China Patent CN104228385A, 24 December 2014.

30. Noda Plywood Mfg. Co. Fabrication of Hydraulic Building Boards. Japan Patent JP60028776B, 6 July 1985.

31. Lin, Y. An Efficient Waste Paper Deinking Agent. China Patent CN105086584A, 25 November 2015.

32. Wang, S.; Zhang, X. Method for Manufacturing Microcapsule with Improved Dye-Releasing Controllability for Image Coating Electronic Ink Used in Electronic Paper. Korea Patent KR2017112154A, 12 October 2017.

33. Sheng, M.; Zhang, L.; Guan, Y.; Li, L.; Fu, S. The photoelectric properties characteristics of dye-doped nematic liquid crystal microcapsules with different structural composition. J. Mol. Liq. 2019, 283, 816-822. [CrossRef]

34. Kim, C.A.; Oh, J. Color Electronic Paper Displays Using Black Matrices and Methods of Fabricating the Same. U.S. Patent US20130163067A1, 27 June 2013.

35. Rodriguez, A.; Batlle, R.; Nerin, C. The use of natural essential oils as antimicrobial solutions in paper packaging. Part II. Prog. Org. Coat. 2017, 60, 33-38. [CrossRef]

36. Manso, S.; Cacho-Nerin, F.; Becerril, R.; Nerín, C. Combined analytical and microbiological tools to study the effect on Aspergillus flavus of cinnamon essential oil contained in food packaging. Food Control 2013, 30, 370-378. [CrossRef]

37. Atarés, L.; Chiralt, A. Essential oils as additives in biodegradable films and coatings for active food packaging. Trends Food Sci. Technol. 2016, 48, 51-62. [CrossRef]

38. Bustos, R.O.; Alberti, F.V.; Matiacevich, S.B. Edible antimicrobial films based on microencapsulated lemongrass oil. J. Food Sci. Technol. 2016, 53, 832-839. [CrossRef]

39. Ribeiro-Santos, R.; Andrade, M.; Sanches-Silva, A. Application of encapsulated essential oils as antimicrobial agents in food packaging. Curr. Opin. Food Sci. 2017, 14, 78-84. [CrossRef]

40. Ribeiro-Santos, R.; Andrade, M.; de Melo, N.R.; Sanches-Silva, A. Use of essential oils in active food packaging: Recent advances and future trends. Trends Food Sci. Technol. 2017, 61, 132-140. [CrossRef]

41. Alarcón-Moyano, J.K.; Bustos, R.O.; Herrera, M.L.; Matiacevich, S.B. Alginate edible films containing microencapsulated lemongrass oil or citral: Effect of encapsulating agent and storage time on physical and antimicrobial properties. J. Food Sci. Technol. 2017, 54, 2878-2889. [CrossRef] [PubMed]

42. Sacchetti, G.; Maietti, S.; Muzzoli, M.; Scaglianti, M.; Manfredini, S.; Radice, M.; Bruni, R. Comparative evaluation of 11 essential oils of different origin as functional antioxidants, antiradicals and antimicrobials in foods. Food Chem. 2005, 91, 621-632. [CrossRef]

43. Matasyoh, J.C.; Wagara, I.N.; Nakavuma, J.L. Chemical composition of Cymbopogon citratus essential oil and its effect on mycotoxigenic Aspergillus species. Afr. J. Food Sci. 2011, 5, 138-142. 
44. Bassolé, I.H.N.; Lamien-Meda, A.; Bayala, B.O.L.C.; Obame, L.C.; Ilboudo, A.J.; Franz, C.; Dicko, M.H. Chemical composition and antimicrobial activity of Cymbopogon citratus and Cymbopogon giganteus essential oils alone and in combination. Phytomedicine 2011, 18, 1070-1074. [CrossRef] [PubMed]

45. Fadli, M.; Pagès, J.M.; Mezrioui, N.E.; Abbad, A.; Hassani, L. Artemisia herba-alba Asso and Cymbopogon citratus (DC.) Stapf essential oils and their capability to restore antibiotics efficacy. Ind. Crop. Prod. 2016, 89, 399-404. [CrossRef]

46. Essential Oils Direct. Lemongrass Oil-Material Safety Data Sheet. Available online: https://www. essentialoilsdirect.co.uk/aromatherapy/msds/lemongrass_oil_essential_oil.pdf (accessed on 29 March 2018).

47. Xiao, Z.; Liu, W.; Zhu, G.; Zhou, R.; Niu, Y. A review of the preparation and application of flavour and essential oils microcapsules based on complex coacervation technology. J. Sci. Food Agric. 2014, 94, 1482-1494. [CrossRef]

48. Majeed, H.; Bian, Y.Y.; Ali, B.; Jamil, A.; Majeed, U.; Khan, Q.F.; Fang, Z. Essential oil encapsulations: Uses, procedures, and trends. RSC Adv. 2015, 5, 58449-58463. [CrossRef]

49. El Asbahani, A.; Miladi, K.; Badri, W.; Sala, M.; Addi, E.A.; Casabianca, H.; Elaissari, A. Essential oils: From extraction to encapsulation. Int. J. Pharm. 2015, 483, 220-243. [CrossRef]

50. Bakry, A.M.; Abbas, S.; Ali, B.; Majeed, H.; Abouelwafa, M.Y.; Mousa, A.; Liang, L. Microencapsulation of oils: A comprehensive review of benefits, techniques, and applications. Compr. Rev. Food Sci. Food Saf. 2016, 15, 143-182. [CrossRef]

51. Rodríguez, J.; Martín, M.J.; Ruiz, M.A.; Clares, B. Current encapsulation strategies for bioactive oils: From alimentary to pharmaceutical perspectives. Food Res. Int. 2016, 83, 41-59. [CrossRef]

52. Urbas, R.; Milošević, R.; Kašiković, N.; Pavlović, Ž.; Elesini, U.S. Microcapsules application in graphic arts industry: A review on the state-of-the-art. Iran. Polym. J. 2017, 26, 541-561. [CrossRef]

53. Hsieh, W.C.; Chang, C.P.; Gao, Y.L. Controlled release properties of chitosan encapsulated volatile citronella oil microcapsules by thermal treatments. Colloids Surf. B Biointerfaces 2006, 53, 209-214. [CrossRef] [PubMed]

54. Leimann, F.V.; Gonçalves, O.H.; Machado, R.A.; Bolzan, A. Antimicrobial activity of microencapsulated lemongrass essential oil and the effect of experimental parameters on microcapsules size and morphology. Mater. Sci. Eng. C 2009, 29, 430-436. [CrossRef]

55. Miro Specos, M.M.; Garcia, J.J.; Tornesello, J.; Marino, P.; Vecchia, M.D.; Tesoriero, M.D.; Hermida, L.G. Microencapsulated citronella oil for mosquito repellent finishing of cotton textiles. Trans. R. Soc. Trop. Med. Hyg. 2010, 104, 653-658. [CrossRef]

56. Solomon, B.; Sahle, F.F.; Gebre-Mariam, T.; Asres, K.; Neubert, R.H.H. Microencapsulation of citronella oil for mosquito-repellent application: Formulation and in vitro permeation studies. Eur. J. Pharm. Biopharm. 2012, 80, 61-66. [CrossRef]

57. Liu, C.H.; Zhou, H.J.; Liu, J.Y.; Li, X.T.; Fang, H.; Yang, Z.H. Preparation of antibacterial citronella oil microcapsules and their application in cotton fabrics. Adv. Mater. Res. 2013, 627, 271-274. [CrossRef]

58. Aziz, F.R.A.; Jai, J.; Raslan, R.; Subuki, I. Microencapsulation of citronella oil by complex coacervation using chitosan-gelatine system: Operating design, preparation and characterization. MATEC Web Conf. 2016, 69, 04002. [CrossRef]

59. Bezerra, F.M.; Carmona, O.G.; Carmona, C.G.; Lis, M.J.; de Moraes, F.F. Controlled release of microencapsulated citronella essential oil on cotton and polyester matrices. Cellulose 2016, 23, 1459-1470. [CrossRef]

60. Ribeiro, A.D.; Marques, J.; Forte, M.; Correia, F.C.; Parpot, P.; Oliveira, C.; Alves, G.M. Microencapsulation of citronella oil for solar-activated controlled release as an insect repellent. Appl. Mater. Today 2016, 5, 90-97. [CrossRef]

61. Khounvilay, K.; Estevinho, B.N.; Rocha, F.A.; Oliveira, J.M.; Vicente, A.; Sittikijyothin, W. Microencapsulation of citronella oil with carboxymethylated tamarind gum. Walailak J. Sci. Technol. (WJST) 2017, 15, 515-527.

62. De Matos, E.F.; Scopel, B.S.; Dettmer, A. Citronella essential oil microencapsulation by complex coacervation with leather waste gelatine and sodium alginate. J. Environ. Chem. Eng. 2018, 6, 1989-1994. [CrossRef]

63. Songkro, S.; Yapong, P.; Puechpan, P.; Maneenuan, D.; Boonme, P. Microencapsulation of citronella oil for mosquito repellent: Preparation and evaluation of release characteristics. Songklanakarin J. Sci. Technol. 2018, 40, 767-775. 
64. De Freitas Souza, C.; Rampelotto, C.; Loureiro, B.B.; Pereira, F.A.; Bianchini, A.E.; Corcini, C.D.; Bertolin, K. Effects of dietary microencapsulated Cymbopogon flexuosus essential oil on reproductive-related parameters in male Rhamdia quelen. Fish Physiol. Biochem. 2018, 44, 1253-1264. [CrossRef] [PubMed]

65. Bhatt, L.; Singh, S.S.J. Comparative analysis of lemongrass oil application on textile substrate through microencapsulation and exhaust method. Int. J. Adv. Res. Sci. Eng. 2018, 7, 313-320.

66. Wang, J.; Li, X.; Chen, M.; Chen, Z.; Wu, H.; Zhang, P.; Hu, Y. Fabrication of sustained-release and antibacterial citronella oil-loaded composite microcapsules based on Pickering emulsion templates. J. Appl. Polym. Sci. 2018, 135, 46386. [CrossRef]

67. Vázquez-Sánchez, D.; Cabo, M.L.; Rodríguez-Herrera, J.J. Antimicrobial activity of essential oils against Staphylococcus aureus biofilms. Food Sci. Technol. Int. 2015, 21, 559-570. [CrossRef] [PubMed]

68. Saddiq, A.A.; Khayyat, S.A. Chemical and antimicrobial studies of monoterpene: Citral. Pestic. Biochem. Physiol. 2010, 98, 89-93. [CrossRef]

69. Ohno, T.; Kita, M.; Yamaoka, Y.; Imamura, S.; Yamamoto, T.; Mitsufuji, S.; Imanishi, J. Antimicrobial activity of essential oils against Helicobacter pylori. Helicobacter 2003, 8, 207-215. [CrossRef]

70. Naik, M.I.; Fomda, B.A.; Jaykumar, E.; Bhat, J.A. Antibacterial activity of lemongrass (Cymbopogon citratus) oil against some selected pathogenic bacterias. Asian Pac. J. Trop. Med. 2010, 3, 535-538. [CrossRef]

71. Boh, B.; Knez, E.; Starešinič, M. Microencapsulation of higher hydrocarbon phase change materials by in situ polymerization. J. Microencapsul. 2005, 22, 715-735. [CrossRef]

72. Xing, F.; Cheng, G.; Yi, K.; Ma, L. Nanoencapsulation of capsaicin by complex coacervation of gelatine, acacia, and tannins. J. Appl. Polym. Sci. 2005, 96, 2225-2229. [CrossRef]

73. Sun, G.; Zhang, Z. Mechanical strength of microcapsules made of different wall materials. Int. J. Pharm. 2002, 242, 307-311. [CrossRef]

74. Hu, J.; Chen, H.-Q.; Zhang, Z. Mechanical properties of melamine-formaldehyde microcapsules for self-healing materials. Mater. Chem. Phys. 2009, 118, 63-70. [CrossRef]

75. Pan, X.; York, D.; Preece, J.-A.; Zhang, Z. Size and strength distributions of melamine-formaldehyde microcapsules prepared by membrane emulsification. Powder Technol. 2012, 227, 43-50. [CrossRef]

76. Chung, S.K.; Seo, J.Y.; Lim, J.H.; Park, H.H.; Yea, M.J.; Park, H.J. Microencapsulation of essential oil for insect repellent in food packaging system. J. Food Sci. 2013, 78, E709-E714. [CrossRef]

77. Zhao, H.; Fei, X.; Cao, L.; Zhang, B.; Liu, X. The fabrication of fragrance microcapsules and their sustained and broken release behaviour. Materials 2019, 12, 393. [CrossRef] [PubMed]

78. Donsi, F.; Annunziata, M.; Sessa, M.; Ferrari, G. Nanoencapsulation of essential oils to enhance their antimicrobial activity in foods. LWT-Food Sci. Technol. 2011, 44, 1908-1914. [CrossRef] 